\title{
(2) OPEN ACCESS \\ Effects of sedentary behaviour interventions on biomarkers of cardiometabolic risk in adults: systematic review with meta-analyses
}

\author{
Nyssa T Hadgraft, ${ }^{1,2,3}$ Elisabeth Winkler, ${ }^{3}$ Rachel E Climie, ${ }^{2}$ Megan S Grace, ${ }^{2}$ \\ Lorena Romero, ${ }^{4}$ Neville Owen, ${ }^{1,2,3}$ David Dunstan, 2,5,6,7,8 Genevieve Healy, ${ }^{2,3,9}$ \\ Paddy C Dempsey (1) $1,2,10$
}

- Additional material is published online only. To view please visit the journal online (http://dx.doi.org/10.1136/ bjsports-2019-101154).

For numbered affiliations see end of article.

\section{Correspondence to} Dr Paddy C Dempsey, MRC Epidemiology Unit, Institute of Metabolic Science, University of Cambridge, Cambridge Biomedical Campus, Cambridge, UK;

Paddy.Dempsey@baker.edu.au

NTH and EW contributed equally.

Accepted 11 March 2020 Published Online First 8 April 2020

\section{Check for update}

(C) Author(s) (or their employer(s)) 2021. Re-use permitted under CC BY. Published by BMJ.

To cite: Hadgraft NT, Winkler E, Climie RE, et al. Br J Sports Med 2021:55:144-154

\section{ABSTRACT}

Context/purpose Observational and acute laboratory intervention research has shown that excessive sedentary time is associated adversely with cardiometabolic biomarkers. This systematic review with meta-analyses synthesises results from free living interventions targeting reductions in sedentary behaviour alone or combined with increases in physical activity.

Methods Six electronic databases were searched up to August 2019 for sedentary behaviour interventions in adults lasting for $\geq 7$ days publishing cardiometabolic biomarker outcomes covering body anthropometry, blood pressure, glucose and lipid metabolism, and inflammation (54 studies). The pooled effectiveness of intervention net of control on 15 biomarker outcomes was evaluated using random effects meta-analyses in the studies with control groups not providing other relevant interventions (33 studies; 6-25 interventions analysed).

Results Interventions between 2 weeks and $<6$ months in non-clinical populations from North America, Europe and Australia comprised much of the evidence base. Pooled effects revealed small, significant $(p<0.05)$ beneficial effects on weight $(\approx-0.6 \mathrm{~kg})$, waist circumference $(\approx-0.7 \mathrm{~cm})$, percentage body fat $(\approx-0.3$ $\%)$, systolic blood pressure $(\approx-1.1 \mathrm{~mm} \mathrm{Hg})$, insulin $(\approx-1.4 \mathrm{pM})$ and high-density lipoprotein cholesterol $(\approx 0.04 \mathrm{mM})$. Pooled effects on the other biomarkers ( $p>0.05)$ were also small, and beneficial in direction except for fat-free mass $(\approx 0.0 \mathrm{~kg})$. Heterogeneity ranged widely $\left(I^{2}=0.0-72.9\right)$.

Conclusions Our review of interventions targeting sedentary behaviour reductions alone, or combined with increases in physical activity, found evidence of effectiveness for improving some cardiometabolic risk biomarkers to a small degree. There was insufficient evidence to evaluate inflammation or vascular function. Key limitations to the underlying evidence base include a paucity of high-quality studies, interventions lasting for $\geq 12$ months, sensitive biomarkers and clinical study populations (eg, type 2 diabetes).

PROSPERO trial registration

number CRD42016041742

\section{INTRODUCTION}

Globally, cardiovascular diseases are the leading cause of death and a major cause of disability and lost productivity in adults. ${ }^{12}$ In addition, estimates from 2017 indicate that 451 million people are living with diabetes: a figure projected to rise to 693 million ( $\approx 10 \%$ of the population) by $2045 .^{3}$

The evidence tends to indicate that greater time spent in sedentary behaviour (ie, sitting/reclining at $<1.5$ metabolic equivalents (MET) $)^{4}$ is adversely associated with the risk of cardiovascular disease, type 2 diabetes and some cancers, ${ }^{56}$ and with levels of a range of cardiometabolic risk biomarkers. ${ }^{78}$ A less prolonged sedentary accumulation pattern (ie, more regular breaks, shorter sedentary bouts) has also been associated with lower body mass index (BMI). ${ }^{8}$ It has largely been acute laboratory interventions ( $<7$ days) using structured protocols providing experimental evidence that reducing or breaking up sitting can have beneficial effects on certain cardiometabolic biomarkers. ${ }^{9-12}$ For example, compared with uninterrupted sitting time, adding short bouts of light or moderate intensity activity every 20-30 min (generally over a period of 1-5 days) results in improvements to resting blood pressure, ${ }^{13} 14$ fasting and postprandial glucose ${ }^{15} 16$ and insulin, ${ }^{151718}$ and some lipids. ${ }^{19}$

In recognition of the aforementioned evidence, several countries now, in addition to having guidelines concerning physical activity, include guidelines to reduce the quantity of sedentary behaviour and/ or break it up. ${ }^{20-22} \mathrm{~A}$ variety of intervention strategies have been trialled to reduce adults' levels of sedentary behaviour, particularly in the workplace setting. ${ }^{2324}$ Reviews indicate these interventions are often effective for reducing sedentary behaviour, especially workplace interventions incorporating environmental modification, ideally as part of a multicomponent intervention. ${ }^{23}$ 25-27 What is lacking, however, is an understanding of the nature and extent of health improvements that might be obtained when intervening to reduce sedentary behaviour over longer periods and under free-living conditions. A preliminary evaluation explored this topic (in workplace interventions only) but, having occurred prior to the emergence of several large trials of sedentary behaviour interventions, did not present any meta-analyses and could draw no firm conclusions. $^{28}$

We therefore conducted a systematic review with meta-analyses aiming to synthesise the body of evidence that examined the effectiveness on biomarkers of cardiometabolic risk of $\geq 7$ days interventions that targetted sedentary behaviour (alone or in combination with physical activity) in free-living conditions. We reviewed the evidence on 
body anthropometry, indicators of blood pressure and related haemodynamics, biomarkers relevant to the metabolism of blood glucose and lipids, and inflammatory biomarkers.

\section{METHODS}

This study followed the Preferred Reporting Items for Systematic Reviews and Meta-Analyses (PRISMA) ${ }^{29}$ and the Meta-analysis of Observational Studies in Epidemiology ${ }^{30}$ reporting guidelines.

\section{Search strategy and study selection}

Six electronic databases (Ovid Medline, Ovid Embase, EBM Reviews Cochrane Central, CINAHL, Scopus, Web of Science) were searched systematically from database inception to 27 August 2019 (7 March 2017; 16 February 2018 and, 27 August 2019). A research librarian (LR) conducted an initial search for studies in Medline and Embase and used an analysis of text words and subject terms to develop the search strategies. The final searches were then executed using the appropriate specifications of each database (LR; see online supplementary table S1). Using reference management software (Endnote, Clarivate Analytics, Philadelphia, USA), records were compiled, duplicates were removed, and two authors (NTH and PCD or REC and MSG) performed title and abstract screening and reviewed each full-text article was reviewed against the inclusion criteria. Discrepancies were resolved in consultation with an independent third reviewer (EW).

\section{Inclusion and exclusion criteria}

Inclusion criteria, applied hierarchically, were: (1) reported intervening on sedentary behaviour for $\geq 7$ days; (2) human study; (3) participants all aged $\geq 18$ years; (4) English language; (5) full-length publication; (6) reported as an outcome at least one biomarker of cardiometabolic health, specifically concerning body anthropometry, glucose metabolism, lipid metabolism, blood pressure and related haemodynamics or inflammation (see online supplementary table S2); and, (7) used an intervention study design (single-group preintervention and postintervention, parallel-group design or crossover). To meet criterion (1), the intervention needed to target sedentary behaviour directly or indirectly with replacement of sedentary activity with an alternative (eg, treadmill desks), increasing 'whole-of-day' activity (which includes sedentary) or increasing 'light intensity' activity (which is almost the inverse of sedentary) or similar. Studies that only mentioned intervening on 'physical activity' or exercise could increase these activities at the expense of either sedentary behaviour or light activity, and therefore did not meet criterion (1). Further inclusion criteria for the meta-analyses were: (1) a no-intervention comparison arm (usual care/conditions; attention control) and (2) no other intervention that was likely to provide an appreciable impact on cardiometabolic biomarkers (eg, diet). Physical activity interventions were permitted, since reducing sedentary time very likely increases some form of physical activity as a replacement. Achievement of successful sedentary behavioural change was not considered a requirement for inclusion in the meta-analyses (to avoid potentially overstating effectiveness). Meta-analyses were conducted for each biomarker reported in at least five studies.

\section{Data extraction}

All data were extracted, checked and discrepancies resolved by the review team (NTH, PCD, REC and EW), using standardised rules created a priori. The rules used for regarding extraction, contacting authors for missing or questionable data are in online supplementary table $\mathrm{S} 2$. Study quality was assessed using the risk of bias (RoB) V.2.0 tool. ${ }^{31}$

\section{Statistical analysis}

Analyses were performed in STATA V.16 (StataCorp). Significance was set at $\mathrm{p}<0.05$ (two tailed). Pooled effects were estimated based on intervention effects (mean between-groups difference, in units) for the end-of-intervention endpoint extracted from each intervention, with the standard errors multiplied by $\sqrt{(n+1) / 2}$ whenever there were $\mathrm{n}>1$ eligible sedentary behaviour intervention arms. ${ }^{32}$ Pooled effects were primarily estimated from random effects (Der Simonian Laird) metaanalysis models, with fixed effects results also reported, along with heterogeneity estimates $\left(\mathrm{I}^{2}\right.$ and Cochrane's $\mathrm{Q}$ test) in the forest plots. A range of sensitivity analyses were also performed. Since Begg's test for publication bias can be underpowered, we also reported bias-corrected estimates from Tweedie and Duval's trim and fill method. Leave-one-out sensitivity analyses were performed to consider how dependent conclusions were to any individual study. Meta-regression models, which explored possible sources of heterogeneity, are reported in the manuscript whenever heterogeneity was significant $(\mathrm{p}<0.05)$ or substantial $\left(\mathrm{I}^{2}>0.25\right)$, otherwise in online supplementary material. Characteristics considered were: mean participant age, mean outcome biomarker levels at baseline, degree of intervention effectiveness for sedentary behaviour (intervention effect on overall sedentary time in $\mathrm{h} /$ day), intervention duration ( $\leq 3$ months/3-6 months 1>6 months) and study quality (RoB scores). Unadjusted and age-adjusted models were reported.

\section{RESULTS}

\section{Systematic review}

Study inclusion

Figure 1 shows the PRISMA flow diagram. In total, 23976 articles were identified. Most were rejected at abstract screening, with 267 articles screened as full text. The criteria mostly excluded studies on the basis they were not $\geq 7$ days sedentary behaviour interventions (181/218). Fifty-four studies (55 articles) were included in the systematic review. ${ }^{33-87}$

The population, design and intervention characteristics of the studies are reported in online supplementary table S3 and aggregated in table 1 . Collectively, the 54 studies involved 6330 participants $(48 \%$ women) with sample sizes usually $<100$ $(\mathrm{k}=36)$ and occasionally $>200(\mathrm{k}=8)$, ranging between 12 and 1113. Study populations were recruited from developed nations, mostly English-speaking (table 1) usually from North America $(\mathrm{k}=20$, predominantly the USA), Europe $(\mathrm{k}=19)$, Australia $(\mathrm{k}=10)$ and occasionally from Asia $(\mathrm{k}=4)$ or Africa $(\mathrm{k}=1)$. From what little and inconsistent data was reported on ethnicity, plus the study locations, we infer that most study participants were likely Caucasian or 'white' (variously defined) with a smaller number identifying as African American or African, Hispanic and Asian ethnicities. Study mean ages ranged from 23 years ${ }^{74}$ to 71 years. ${ }^{51}$ Typically, the studies recruited participants from the general population $(\mathrm{k}=26)$ or a population with a chronic disease risk factor $(k=17)$ (generally overweight and/or obesity, occasionally in conjunction with another risk factor). Clinical conditions $^{36} 37394448596071728184$ were seldom targeted for recruitment; of these only some conditions were pertinent to cardiovascular health. Many studies $(k=25)$ used screening to recruit participants at risk for high sedentary behaviour based on their job (eg, office or desk-based work) and/or their reported 

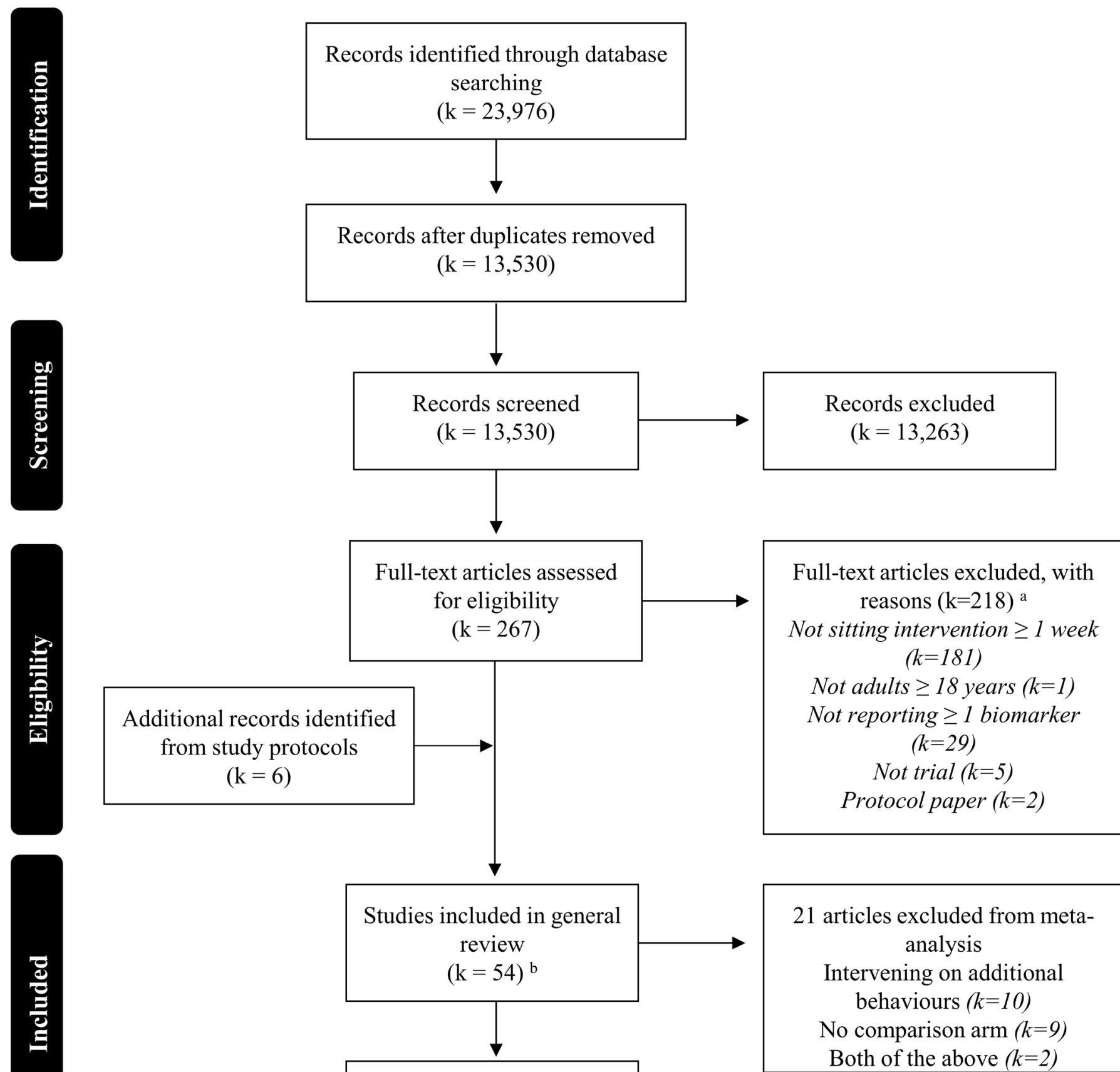

Studies included in metaanalyses $(\mathrm{k}=33)^{\mathrm{c}}$

Figure 1 PRISMA diagram of the literature search results. ${ }^{a}$ Exclusion criteria were applied in the following order: (1) not sitting intervention $\geq 1$ week, (2) not a human study, (3) not English language, (4) not full-length publication, (5) not reporting $\geq 1$ biomarker, (6) not randomised, quasirandomised or pre-post trial, (7) not adults $\geq 18$ years. ${ }^{b}$ Two articles were identified for one study (Balducci et al ${ }_{1}^{47}$ Balducci et al ${ }^{72}$ ). ${ }^{C} \mathrm{k}=32$ for anthropometry measures; $k=25$ for blood pressure measures; $k=22$ for glucose measures; $k=24$ lipid measures; $k=4$ inflammatory measures. PRISMA, Preferred Reporting Items for Systematic Reviews and Meta-Analyses.

behaviours, while 20 studies screened based on physical activity, and 11 studies screened on both behaviours.

\section{Interventions}

The 54 studies delivered 56 sedentary behaviour interventions, mostly in the workplace $(k=27)$ or community $(k=18)$ settings, with healthcare $(\mathrm{k}=9)$, domestic $(\mathrm{k}=1)$ and educational settings $(k=1)$ being less common (table 1 , details in online supplementary table S3). Workplace interventions were about half multicomponent $(k=13)$ and half single component $(k=14)$, while interventions in the remaining non-workplace settings were mostly multicomponent $(\mathrm{k}=21,72 \%)$. Workplace interventions almost all used environmental modification $(k=26)$, commonly used counselling/education $(\mathrm{k}=13)$, sometimes used device self-monitoring $(\mathrm{k}=5)$, device-based social comparison $(\mathrm{k}=3)$, prompting via devices or SMS $(\mathrm{k}=6)$ and structured 
Table 1 Summary of the study population, design and intervention characteristics of adult sedentary behaviour interventions $\geq 7$ days with biomarker outcomes

\begin{tabular}{|c|c|c|c|}
\hline Characteristic & & Count* & Detail \\
\hline \multicolumn{4}{|c|}{ Population / study characteristics (54 studies) } \\
\hline \multirow[t]{2}{*}{ Sample size } & Median $\mathrm{n} /$ study & 57 & Lowest=12, highest=1113 \\
\hline & Total $n$ & 5217 & $\begin{array}{l}\text { Female } n=3065(48.4 \%) \\
\text { male } n=3265(51.6 \%)\end{array}$ \\
\hline \multirow{5}{*}{$\begin{array}{l}\text { Location } \\
\text { (continent and } \\
\text { country: ISO } \\
\text { 2-digit country } \\
\text { codes) }\end{array}$} & North America & 20 & USA 16, CA 4 \\
\hline & Europe & 19 & $\begin{array}{l}\text { UK 5, DK 4, SE 3, ES 2, NL 1, } \\
\text { DK \& GL 1, FI 1, IT 1, UK \& } \\
\text { NL \& NO \& PT } 1\end{array}$ \\
\hline & Australia & 10 & \\
\hline & Asia & 4 & TW 2, CN 1, JP 1 \\
\hline & Africa & 1 & ZA 1 \\
\hline \multirow[t]{3}{*}{ Ethnicity } & $\begin{array}{l}>50 \% \text { Caucasian / } \\
\text { 'white' }\end{array}$ & 18 & \\
\hline & $\begin{array}{l}<50 \% \text { Caucasian / } \\
\text { 'white' }\end{array}$ & 2 & \\
\hline & Not reported & 33 & \\
\hline \multirow[t]{3}{*}{$\begin{array}{l}\text { Clinical } \\
\text { population }\end{array}$} & Clinical condition & 11 & $\begin{array}{l}\text { T2D 4, cancer 2, rheumatoid } \\
\text { arthritis 2, obstructive } \\
\text { sleep apnoea 1, intellectual } \\
\text { disability 1, coronary artery } \\
\text { disease } 1\end{array}$ \\
\hline & Clinical risk factors only & 17 & $\begin{array}{l}\text { Adiposity 14, chronic disease } \\
\text { risk (+adiposity) } 3\end{array}$ \\
\hline & Healthy / general & 26 & \\
\hline \multirow[t]{2}{*}{ Screening } & $\begin{array}{l}\text { Sedentary job / } \\
\text { behaviour }\end{array}$ & 25 & $\begin{array}{l}11 \text { also screened for PA, } 14 \\
\text { did not }\end{array}$ \\
\hline & Physical activity (PA) & 30 & $\begin{array}{l}11 \text { also screened for PA, } 19 \\
\text { did not }\end{array}$ \\
\hline \multirow[t]{4}{*}{ Study design } & $\begin{array}{l}\text { Randomised controlled } \\
\text { trial }\end{array}$ & 39 & $\begin{array}{l}8 \text { cluster / } 31 \text { individually } \\
\text { randomised } \\
34 \text { parallel group / } 3 \\
\text { crossover / } 1 \text { other } \dagger\end{array}$ \\
\hline & $\begin{array}{l}\text { Non-randomised } \\
\text { controlled trial }\end{array}$ & 5 & $\begin{array}{l}1 \text { cluster / } 4 \text { individually } \\
\text { allocated } \\
5 \text { parallel group / } 0 \text { crossover }\end{array}$ \\
\hline & Multiarm (no controls) & 5 & $\begin{array}{l}1 \text { cluster randomised / } 4 \\
\text { individually randomised }\end{array}$ \\
\hline & Pre-post (single arm) & 5 & \\
\hline \multirow{4}{*}{$\begin{array}{l}\text { Primary } \\
\text { outcomes }\end{array}$} & Includes sedentary & 22 & \\
\hline & Includes biomarker(s) & 10 & \\
\hline & Includes both & 1 & \\
\hline & Includes neither & 21 & $\begin{array}{l}\text { PA } 8 \text { / PA and diet } 1 \text {, } \\
\text { unstated } 6 \text {, feasibility } 5 \text {, } \\
\text { fitness } 1\end{array}$ \\
\hline \multicolumn{4}{|c|}{ Intervention characteristics (56 interventions) } \\
\hline \multirow[t]{3}{*}{ Duration } & 3 months or less & 28 & \\
\hline & $>3$ to 6 months & 16 & \\
\hline & $>6$ months & 12 & \\
\hline \multirow[t]{3}{*}{ Setting } & Workplace & 27 & \\
\hline & Community & 18 & \\
\hline & Other & 11 & $\begin{array}{l}\text { Hospital 5, primary care } 4 \text {, } \\
\text { domestic } 1 \text {, education } 1\end{array}$ \\
\hline \multirow[t]{2}{*}{$\mathrm{N}$ components } & Multicomponent & 34 & $\begin{array}{l}\text { Workplace 13, community / } \\
\text { other } 21\end{array}$ \\
\hline & Single component & 22 & $\begin{array}{l}\text { Workplace } 14 \text {, community } \\
\text { / other } 8\end{array}$ \\
\hline
\end{tabular}

Continued
Table 1 Continued

\begin{tabular}{|c|c|c|c|}
\hline Characteristic & & Count* & Detail \\
\hline \multirow[t]{7}{*}{ Components $\ddagger$} & Counselling / education & 41 & $\begin{array}{l}\text { Workplace 13, community / } \\
\text { other } 28\end{array}$ \\
\hline & $\begin{array}{l}\text { Environmental } \\
\text { modification }\end{array}$ & 34 & $\begin{array}{l}\text { Workplace } 26 \text {, community } \\
\text { / other } 8\end{array}$ \\
\hline & Prompting & 12 & $\begin{array}{l}\text { Workplace 6, community / } \\
\text { other } 6\end{array}$ \\
\hline & Structured 'activity' & 5 & $\begin{array}{l}\text { Workplace 2, community / } \\
\text { other } 4\end{array}$ \\
\hline & Device self-monitoring & 23 & $\begin{array}{l}\text { Workplace 5, community / } \\
\text { other } 18\end{array}$ \\
\hline & $\begin{array}{l}\text { Device social } \\
\text { comparison }\end{array}$ & 7 & $\begin{array}{l}\text { Workplace 3, community / } \\
\text { other } 4\end{array}$ \\
\hline & Financial incentives & 2 & $\begin{array}{l}\text { Workplace 1, community / } \\
\text { other } 1\end{array}$ \\
\hline \multirow{3}{*}{$\begin{array}{l}\text { Sedentary } \\
\text { targets / } \\
\text { messaging } \ddagger\end{array}$} & $\begin{array}{l}\text { Domain specific } \\
\text { message }\end{array}$ & 29 & \\
\hline & Accumulation & 21 & \\
\hline & $\begin{array}{l}\text { Quantitative volume } \\
\text { target }\end{array}$ & 14 & \\
\hline
\end{tabular}

${ }^{*}$ Count out of 54 studies or 56 interventions as indicated in the table unless other statistic is mentioned (eg, median).

†Almost a randomised controlled trial (parallel groups) except re-enrolled some controls into the intervention on completion.

$\ddagger$ Not mutually exclusive (interventions can have multiple components, multiple messages).

T2D, type 2 diabetes.

activity sessions $(\mathrm{k}=2)$. By contrast, non-workplace interventions almost always used some form of counselling/education $(k=29)$, commonly used device self-monitoring $(k=18)$ and occasionally used environmental modification $(\mathrm{k}=8)$, prompting $(\mathrm{k}=6)$, structured activity $(\mathrm{k}=4)$ and financial incentives $(\mathrm{k}=1)$. The extent of education or counselling was also highly variable, ranging from brief advice to theoretically grounded behavioural counselling.

The interventions varied in how they considered sedentary behaviour. Diverse behaviours were promoted as replacements for sedentary behaviour: primarily standing, walking or other stepping, but also sometimes pedalling, 'incidental' exercise (likely predominantly 'light' activities), activities of moderate or greater intensity and sometimes resistance exercise (online supplementary table S3). Sedentary behaviour targets seldom were domain specific, referenced accumulation patterns or set quantitative guidelines on sedentary time (table 1). Primary outcomes included sedentary behaviour in 23 studies, biomarkers in 11 , and included neither in 20, instead being unstated $(\mathrm{k}=6)$, focused on feasibility $(k=5)$ or involving physical activity with or without other outcomes $(k=9)$.

\section{Evaluation of biomarker indicators of cardiovascular health}

The biomarkers selected for review are shown in table 2 . Biomarker outcomes nearly always included indicators of body anthropometry ( $k=52$ studies), and often included indicators of blood pressure $(k=37)$, lipid metabolism $(k=33)$ and glucose metabolism $(\mathrm{k}=31)$. Four studies reported on $\mathrm{C}$ reactive protein. $^{72} 737587$ Other inflammatory markers, such as tumour necrosis factor $\alpha$ or interleukin- 6 , were not found among the reported outcomes.

Of the anthropometric indicators, the most commonly reported were weight $(\mathrm{k}=45)$ or BMI $(\mathrm{k}=39)$, followed by waist circumference $(\mathrm{k}=37)$. These were almost always collected 
Table 2 Biomarkers reported as outcomes in 54 studies of adult sedentary behaviour interventions $\geq 7$ days

\begin{tabular}{|c|c|c|c|}
\hline Outcomes & Studies & Detail & Quality factors \\
\hline Body anthropometry & 52 & & \\
\hline Body weight* & 45 & $45 \mathrm{wt}^{\star}, 39$ body mass index $\mathrm{BMI}^{*}$ & Objectivet / self-report: 44/1 \\
\hline Waist circumference* & 37 & 37 circumference ${ }^{*}, 2$ waist:hip ratio & \multirow[t]{2}{*}{ Objectivet / self-report: $36 / 1$} \\
\hline Other body measurements & 9 & 7 hip circumference, 1 neck circumference, 2 sagittal abdominal diameter & \\
\hline Body composition & 25 & & \multirow{4}{*}{$\begin{array}{l}\text { BIA: } 12 \\
\text { DXA: } 5 \\
\text { BIS: } 2 \\
\text { BADP: } 3 \\
\text { Skinfold(s): } 2 \\
\text { Unreported: } 1\end{array}$} \\
\hline Total fat & 25 & 20 percentage of body weight* ${ }^{*}, 11$ mass* & \\
\hline Total fat-free or lean & 13 & 12 percentage of body weight, 1 mass*, & \\
\hline Other & 5 & $\begin{array}{l}\text { fat mass or } \% \text { ( } 4 \text { truncal, } 1 \text { arm, } 1 \text { leg, } 1 \text { android } \%, 1 \text { gynoid \%); fat-free mass } \\
\text { or \% (1 arm, } 1 \text { leg); } 1 \text { skeletal muscle mass; } 1 \text { visceral fat area }\end{array}$ & \\
\hline Blood pressure (BP) regulation & 37 & & \\
\hline Resting BP * & 37 & 37 systolic*, 36 diastolic*, two mean arterial BP & Objectivet / self-report: 36/1 \\
\hline Ambulatory BP & 0 & - & - \\
\hline Heart rate & 5 & 3 resting, 2 non-resting & Objectivet / self-report: 5/0 \\
\hline Detailed vascular health measures & 3 & $\begin{array}{l}1 \text { flow mediated dilation, } 1 \text { carotid intima media thickness, } 1 \text { aortic } \\
\text { augmentation index, } 1 \text { subendocardial variability, } 1 \text { pulse wave velocity }\end{array}$ & Objective $/$ self-report: $3 / 0$ \\
\hline Glucose metabolism & 31 & & \multirow{4}{*}{ Venous / capillary: 20/7 } \\
\hline Fasting glucose* & 27 & & \\
\hline Fasting insulin* & 13 & & \\
\hline HOMA / HOMA-2 & 7 & 6 HOMA-IR, 2 HOMA-\%B, 1 HOMA2-\%B, 1 HOMA2-\%S & \\
\hline Postprandial glucose / insulin & 4 & $\begin{array}{l}4 \text { postprandial glucose, } 1 \text { postprandial insulin, } 1 \text { insulin AUC, } 1 \text { glucose AUC, } 1 \\
\text { C-ISI }\end{array}$ & $\begin{array}{l}\text { Venous / capillary: } 4 / 0 \\
\text { Duration: all } 2 \text { hours test }\end{array}$ \\
\hline C-peptide & 0 & & - \\
\hline $\mathrm{HbA1} \mathrm{c}^{*}$ & 17 & $15 \mathrm{HbA} 1 \mathrm{c}, 2$ 'estimated average glucose' reported as $\mathrm{HbA1c}$ & Venous / capillary: 15/2 \\
\hline Lipid metabolism & 33 & & \\
\hline Cholesterol levels or ratios & 33 & 29 total $^{*}, 28 \mathrm{HDL}^{*}, 24 \mathrm{LDL}^{*}, 1 \mathrm{VLDL}, 1$ non-LDL, 5 total/HDL, 2 LDL/HDL & \multirow{3}{*}{$\begin{array}{l}\text { Venous / capillary: } 25 / 8 \\
\text { fasted / insufficient / non-fasted state: } \\
25 / 1 / 7\end{array}$} \\
\hline Triglycerides* & 32 & & \\
\hline Other & 3 & $\begin{array}{l}1 \text { cholesterol diameter; } 1 \text { lipoprotein lipase; } 3 \text { apolipoproteins (APO): } 3 \text { APO-A1, } \\
3 \text { APO-B, } 2 \text { APO-A1/APO-B }\end{array}$ & \\
\hline Inflammation & 4 & & \\
\hline C reactive protein (CRP) & 4 & 2 CRP; two high-sensitivity CRP & $\begin{array}{l}\text { Venous / capillary: } 4 / 0 \\
\text { fasted / insufficient / non-fasted state: } \\
4 / 0 / 0\end{array}$ \\
\hline Other: TNF- $\alpha$, IL- 6 & 0 & & - \\
\hline
\end{tabular}

Data were extracted from the earlier paper related to this study Balducci 2017 when it was not reported in the 2019 paper (body fat percentage; fat-free mass; BMl; fasting insulin; HOMA).

*Outcome included in the meta-analyses: was reported in $>5$ of the 33 studies eligible for the effectiveness meta-analyses (had control arm, no additional relevant intervention provided apart from active behaviours).

tMeasured objectively by research staff.

AUC, area under the curve; BADP, body air displacement plethysmography; BIA, multifrequency bioimpedance analysis; BIS, bioelectrical impedance spectroscopy; BMI, body mass index; C-ISI, composite insulin sensitivity index; DXA, dual X-ray absorptiometry; HDL, high-density lipoprotein; HOMA-2, revised homeostatic model assessment; HOMA, homeostatic model assessment; IL-6, interleukin 6; LDL, low-density lipoprotein; TNF- $\alpha$, tumour necrosis factor $\alpha$; VLDL, very-low-density lipoprotein.

objectively by staff. Body composition outcomes were collected mostly using multifrequency bioimpedance analysis $(\mathrm{k}=12)$ or reference-grade standards: dual X-ray absorptiometry $(\mathrm{k}=5)$ or body air displacement plethysmography $(\mathrm{k}=3)$. Occasionally, other methods were used $(k=4)$. Studies typically reported on body fat $(k=25)$ (most commonly as percentage of body weight), and occasionally fat-free, lean or muscle mass $(k=13)$. Thus, fewer studies were able to assess changes to specific tissues (eg, fat, lean tissue) or anatomical sites (eg, truncal fat, measured in four studies).

Blood pressure was generally assessed with resting blood pressure $(k=37)$, which was typically reported separately as systolic $(k=37)$ and/or diastolic blood pressure $(k=36)$ and as mean arterial pressure in two studies ${ }^{57}$ (table 2). Usually, staff measured blood pressure, with participants reporting values from home monitors in one study. ${ }^{46}$ Ambulatory blood pressure was not reported. Detailed biomarkers of vascular health (eg, endothelial dysfunction, arterial stiffness) were seldom collected. One study reported on flow mediated dilatation, carotid artery intima media thickness, aortic augmentation index and sub endocardial variability. ${ }^{53}$ Resting heart rate was collected in three studies. ${ }^{62} 6973$

Of the glucose metabolism indicators (table 2$)$, most $(k=27)$ reported on fasting glucose, with only 13 reporting fasting insulin, and 7 reporting composite indicators of beta-cell function or insulin resistance (ie, measures from homeostatic model assessment, HOMA or HOMA-2). Seventeen studies reported on overall glucose control (HbA1c expressed in various forms), while four studies reported effects on postprandial glucose and/ or insulin 54587183 and none reported on c-peptide. While venous blood draws were the norm for collecting fasting values $(k=20$ studies), lower quality fingerstick capillary measures were occasionally used $(k=7)$. None of the studies reported outcomes from continuous glucose monitoring.

The most commonly reported lipid markers were: triglycerides $(\mathrm{k}=32)$; total cholesterol $(\mathrm{k}=29)$; high-density lipoprotein (HDL) cholesterol $(\mathrm{k}=28)$ and, low-density lipoprotein (LDL) 
cholesterol $(\mathrm{k}=24)$ (table 2$)$. These markers are reported widely in the context of cardiovascular risk. Studies occasionally reported VLDL cholesterol, ${ }^{69}$ non-LDL cholesterol ${ }^{40}$ or cholesterol ratios. ${ }^{4042} 436070$ Three studies reported on apolipoproteins (APOA1, APOB and their ratio ${ }^{387073}$ ) and one reported on the diameter of various types of cholesterol. ${ }^{38}$ None of the studies mentioned performing detailed profiling of lipid classes or subclasses.

\section{Study designs}

Very few studies $(\mathrm{k}=5)$ used a single-group pre-post study

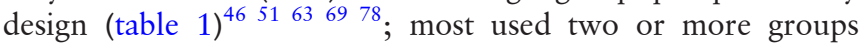
$(\mathrm{k}=49)$. Usually the additional group (or groups) facilitated testing effectiveness against a no-intervention or attention control comparison arm ( $k=44$, with 39 randomised) or occasionally only allowed for comparison of alternate interventions ( $k=5$, with five randomised). ${ }^{34} 44506784$ Most studies $(k=42)$ intervened for 6 months or less (shortest $=2$ weeks) while few $(k=10)$ intervened for 12 months or longer ${ }^{43} 444659606372737687$ (longest $=36$ months). Only nine studies referred to evaluation of maintenance of effects following withdrawal of intervention or intervention contact.

\section{Meta-analysis}

Study inclusion

Of the 44 controlled intervention studies, 33 studies (34 interventions) were eligible for the meta-analyses (11 studies had provided diet intervention). For the 15 biomarkers that met the inclusion criteria (table 2), the number of studies providing data and able to be included ranged from 6 for fat mass to 25 for body weight and blood pressure, and these studies collectively represented anywhere between 724 and 2076 participants.

\section{Risk of bias}

RoB overall is reported in online supplementary table S6. To simplify reporting, criteria scored for groups of outcomes with similar concerns underlying their bias risk (eg, missing data, measurement): anthropometric and blood pressure outcomes, glucose metabolism outcomes and lipid metabolism outcomes. Overall RoB was high ( $\geq 1$ criteria was 'high' risk) in 10 studies (30\%), unclear (ie, 0 'high' risk and $\geq 1$ 'unclear' risk) in 17 $(52 \%)$ studies and 'low' (ie, all 'low' risk) in 6 studies (18\%). The most common contributor to a 'high' RoB rating related to the randomisation process $\left(\mathrm{k}=6,18 \%\right.$ ), ${ }^{586468767987}$ (ie, use of non-random methods). Four studies were also rated as 'high' RoB due to deviations from intended interventions (data not analysed according to intention-to-treat principles ${ }^{4058} 7479$ ) and missing outcome data. ${ }^{76798387}$ An unclear risk level was typically assigned based on inadequate reporting of randomisation $(k=12)$, concerns with missing outcome data $(k=11)$ and/or bias in measurement of the outcome $(k=9)$. Low risk was still permitted with lack of blinding, given the context (behavioural intervention) in which allocation is impossible to conceal from participants and is generally known to staff, and in which outcomes are collected objectively.

\section{Effectiveness of sedentary behaviour interventions for biomarker outcomes}

Effects on biomarkers were evaluated in the context of interventions that had displayed overall sedentary time improvements net of control that were mostly moderate $(\mathrm{k}=12,30$ to $<60 \mathrm{~min} /$ day), otherwise strong $(\mathrm{k}=9, \geq 60 \mathrm{~min} /$ day) or small (15 to $<30 \mathrm{~min} /$ day, $\mathrm{k}=8)$ or occasionally almost zero $(\mathrm{k}=3,-15$ to
$<15 \mathrm{~min} /$ day). Effects ranged from +11.3 to $-132 \mathrm{~min} /$ day (see online supplementary table S4). Table 3 shows the pooled effects on biomarkers for the main analyses and sensitivity analyses. Begg's tests were all $p \geq 0.05$ (online supplementary table S7).

\section{Body weight and body composition}

Consistent with the studies' selection criteria, prior to intervention, participants had a weighted mean ( \pm pooled SD) BMI of $25.4 \pm 3.2 \mathrm{~kg} / \mathrm{m}^{2}$, with study means ranging from $22.1 \mathrm{~kg} / \mathrm{m}^{2}$ in a workplace intervention with no weight screening criteria ${ }^{68}$ to $35.9 \mathrm{~kg} / \mathrm{m}^{2}$ in a treadmill intervention for overweight/obese office workers. ${ }^{56}$ Baseline anthropometric values are summarised in table 4 (detail in online supplementary table S4). Pooled effects showed that the sedentary behaviour interventions tended to provide small improvements (net of control) in body anthropometry outcomes (table 3). Significant pooled effects in favour of intervention were seen regarding body weight $(-0.56 \mathrm{~kg}$, $95 \%$ CI -0.94 to 0.17$)$, waist circumference $(-0.72 \mathrm{~cm}, 95 \% \mathrm{CI}$ -1.21 to 0.22$)$, body fat percentage $(-0.26 \%, 95 \% \mathrm{CI}-0.50 \%$ to $0.02 \%)$, with a tendency towards reduced fat mass $(-0.33 \mathrm{~kg}$, $95 \% \mathrm{CI}-0.74$ to 0.08$)$ and no large or significant effect on fat-free mass $(0.00 \mathrm{~kg}, 95 \% \mathrm{CI}-0.52$ to 0.53$)$. Effects on BMI were in a similar direction to those for body weight, but not statistically significant $\left(-0.07 \mathrm{~kg} / \mathrm{m}^{2}, 95 \% \mathrm{CI}-0.16\right.$ to 0.03$)$. Forest plots for body weight and body composition are shown in online supplementary figure 1-6. Small-study effects did not lead to overstated findings, as the original findings were no more favourable than the trimmed and filled results. Also, no single study seemed to overly influence the conclusions, as improvements observed were always still present to some degree in the leave-one-out sensitivity analyses.

Body weight and body fat percentage showed little evidence of heterogeneity $\left(\mathrm{I}^{2}<25 \% ; \mathrm{p} \geq 0.05\right)$ with slightly more substantial (but non-significant) heterogeneity seen for fat mass and significant heterogeneity seen for waist circumference and fatfree mass. The heterogeneity in effects on fat-free mass was completely attenuated $\left(\mathrm{I}^{2}=0.0, \mathrm{p}=0.790\right)$ by omitting a single study. ${ }^{45}$ Omission of this same study partially attenuated heterogeneity in effects on waist circumference $\left(\mathrm{I}^{2}=19.9 \%, \mathrm{p}=0.217\right)$. Further exploration of the heterogeneity via meta-regression (table 5) did not show any significant predictors of effects on waist circumference. The largest effects and the smallest residual heterogeneity were seen for RoB scores (residual $\mathrm{I}^{2}=22.6 \%$, $\mathrm{p}=0.192$ ), with effects stronger by just over $1 \mathrm{~cm}$ in studies with high versus low RoB. Meta-regression results for the outcomes not displaying substantial or significant heterogeneity are shown in online supplementary table S8.

\section{Blood pressure}

Prior to intervention, participants had a weighted mean ( \pm pooled SD) blood pressure of $110.0 \pm 10.5 \mathrm{~mm} \mathrm{Hg}$ systolic and $78.4 \pm 7.1 \mathrm{~mm} \mathrm{Hg}$ diastolic, indicating typically healthy levels, though with some studies attracting samples with average systolic blood pressure as high as $140 \mathrm{~mm} \mathrm{Hg}$ or higher ${ }^{55} 70$ (table 3 and online supplementary table S4). Pooled effects showed a small significant reduction in systolic blood pressure $(-1.05 \mathrm{~mm} \mathrm{Hg}$, $95 \% \mathrm{CI}-2.08$ to 0.02 ) and a smaller non-significant reduction in diastolic blood pressure $(-0.69 \mathrm{~mm} \mathrm{Hg}, 95 \% \mathrm{CI}-1.69$ to 0.32 ; table 3 ). Forest plots are shown in online supplementary figure $\mathrm{S} 7$ and online supplementary figure 8 . Corrections for small-study effects had no effect on the results and pooled effects consistently reflected tendencies towards reduced blood pressure in the leave-one-out sensitivity analyses. Heterogeneity 
Table 3 Pooled intervention effects on biomarkers: controlled trials of 34 adult sedentary behaviour interventions $\geq 7$ days

\begin{tabular}{|c|c|c|c|c|c|c|c|c|}
\hline \multirow[b]{3}{*}{ Outcome } & \multicolumn{5}{|c|}{ Main findings } & \multirow{3}{*}{$\begin{array}{l}\text { Publication-bias } \\
\text { corrected } \\
\text { Pooled }(95 \% \mathrm{Cl})\end{array}$} & \multicolumn{2}{|c|}{ Leave-one-out sensitivity analysis } \\
\hline & \multirow[b]{2}{*}{ k } & \multirow[b]{2}{*}{ n } & \multicolumn{3}{|l|}{ All studies } & & \multirow{2}{*}{$\begin{array}{l}\text { Most benefit } \\
\text { Pooled effect }(95 \% \mathrm{Cl})\end{array}$} & \multirow{2}{*}{$\begin{array}{l}\text { Least benefit } \\
\text { Pooled effect }(95 \% \mathrm{Cl})\end{array}$} \\
\hline & & & $\mathrm{I}^{2}, \mathrm{P}$ value & Pooled effect $(95 \% \mathrm{Cl})$ & $P$ value & & & \\
\hline Weight, kg & 25 & 1839 & $23.6 \%, p=0.142$ & $-0.56(-0.94$ to -0.17$)$ & 0.005 & $\mathrm{n} / \mathrm{a}$ & $-0.63(-1.03 \text { to }-0.23)^{*}$ & $-0.47(-0.75$ to -0.18$) \dagger$ \\
\hline Body mass index, $\mathrm{kg} / \mathrm{m}^{2}$ & 24 & 1843 & $0.0 \%, p=0.804$ & $-0.07(-0.16$ to 0.03$)$ & 0.167 & $-0.08(-0.17$ to 0.02$)$ & $-0.10(-0.20$ to 0.01$) \ddagger$ & $-0.04(-0.14$ to 0.06$) \S$ \\
\hline Waist circumference, cm & 19 & 2076 & $45.8 \%, p=0.016$ & $-0.72(-1.21$ to -0.22$)$ & 0.004 & $-1.00(-1.51$ to -0.49$)$ & $-0.95(-1.38$ to -0.51$) \eta^{* *}$ & $-0.61(-1.20$ to -0.01$)$ १ $+\dagger$ \\
\hline Body fat, $\%$ & 16 & 1618 & $5.5 \%, p=0.390$ & $-0.26(-0.50$ to -0.02$)$ & 0.034 & $-0.37(-0.65$ to -0.10$)$ & $-0.37(-0.61$ to -0.12$) \ddagger$ & $-0.17(-0.43 \text { to } 0.09)^{* *}$ \\
\hline Fat mass, kg & 6 & 724 & $26.6 \%, p=0.235$ & $-0.33(-0.74$ to 0.08$)$ & 0.116 & $\mathrm{n} / \mathrm{a}$ & $-0.42(-0.73$ to -0.10$) \ddagger \ddagger$ & $-0.23(-0.63$ to 0.16$) \S \S$ \\
\hline Fat-free mass, kg & 7 & 1011 & $72.7 \%, p=0.001$ & $0.00(-0.52$ to 0.53$)$ & 0.992 & $0.48(-0.02$ to 0.98$)$ & $0.12(-0.40$ to 0.65$) \ddagger$ & $-0.25(-0.57$ to 0.06$) \eta^{* *}$ \\
\hline \multicolumn{9}{|l|}{ Blood pressure, mm Hg } \\
\hline Systolic & 25 & 1932 & $8.6 \%, p=0.341$ & $-1.05(-2.08$ to -0.02$)$ & 0.045 & $\mathrm{n} / \mathrm{a}$ & $-1.42(-2.38$ to -0.45$) \ddagger$ & $-0.75(-1.81$ to 0.31$)$ १ा \\
\hline Diastolic & 25 & 1932 & $52.6 \%, p=0.001$ & $-0.69(-1.69$ to 0.32$)$ & 0.180 & $\mathrm{n} / \mathrm{a}$ & $-0.92(-1.86 \text { to } 0.02)^{* * *}$ & $-0.36(-1.28$ to 0.56$)+t \dagger$ \\
\hline Glucose, mM & 19 & 1518 & $45.5 \%, p=0.017$ & $-0.03(-0.11$ to 0.05$)$ & 0.526 & $-0.04(-0.13$ to 0.05$)$ & $-0.05(-0.11$ to 0.02$)$ 抹 & $-0.01(-0.11$ to 0.09$)$ ๆी \\
\hline Insulin, pM & 10 & 1102 & $64.0 \%, p=0.003$ & $-1.42(-2.82$ to -0.02$)$ & 0.047 & $-1.03(-2.48$ to 0.42$)$ & $-4.13(-7.48$ to -0.78$) \S \S \S$ & $-0.45(-1.60$ to 0.69$) q^{*}$ \\
\hline $\mathrm{HbA} 1 \mathrm{c}, \%$ & 9 & 892 & $72.9 \%, p=0.000$ & $-0.10(-0.22$ to 0.03$)$ & 0.129 & $-0.03(-0.16$ to 0.09$)$ & $-0.14(-0.29$ to 0.01$)$ ๆาा & $-0.05(-0.17$ to 0.07$) \S \S$ \\
\hline \multicolumn{9}{|l|}{ Cholesterol, mM } \\
\hline Total & 23 & 1798 & $54.1 \%, p=0.001$ & $-0.06(-0.16$ to 0.04$)$ & 0.213 & $-0.10(-0.20$ to -0.00$)$ & $-0.08(-0.18$ to 0.02$) \ddagger \ddagger \ddagger$ & $-0.03(-0.11$ to 0.05$) \eta^{* * * *}$ \\
\hline High-density lipoprotein & 22 & 1760 & $22.5 \%, p=0.168$ & $0.04(0.02$ to 0.07$)$ & $<0.001$ & $0.05(0.02$ to 0.07$)$ & $0.05(0.03$ to 0.07$) \S$ & 0.03 (0.01 to 0.06$)$ ת \\
\hline Low-density lipoprotein & 20 & 1660 & $0.0 \%, p=0.690$ & $-0.02(-0.07$ to 0.04$)$ & 0.562 & $-0.01(-0.07$ to 0.05$)$ & $-0.03(-0.09$ to 0.03$) \ddagger \ddagger \ddagger$ & $-0.00(-0.06$ to 0.06$)+t \dagger \dagger$ \\
\hline Triglycerides, mM & 23 & 1742 & $49.0 \%, p=0.005$ & $-0.02(-0.09$ to 0.04$)$ & 0.496 & $-0.06(-0.13$ to 0.01$)$ & $-0.04(-0.10$ to 0.03$) \neq \ddagger$ & $-0.01(-0.07$ to 0.06$) \S \S$ \\
\hline
\end{tabular}

$\mathrm{k}, \mathrm{n}=$ number of interventions, number of individuals (sum of $\mathrm{n}$ analysed in each included study).

Boldface indicates pooled effect is $p<0.05$.

* Omitted Healy et al (2017).

tOmitted Ashe et al (2015).

$\ddagger$ Omitted Maylor et al (2018).

§Omitted Pesola et al (2017).

IHeterogeneity no longer $p<0.05$ in leave-one-out sensitivity analysis.

** Omitted Danquah et al (2017).

††Omitted Puig-Ribera et al (2015).

$\$ \neq$ Omitted Healy et al (2013).

$\S \S 0$ mitted Kallings et al (2017).

१९ा Omitted Butler et al (2018).

$* * *$ Omitted Mantzari et al (2018)

†††Omitted Lin et al (2017).

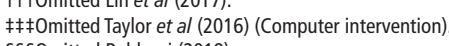

$\S \S \S 0$ mitted Balducci (2019).

ๆी११Omitted Biddle (2015).

$* * * *$ Omitted Thomsen et al (2017).

††††Omitted Aadahl et al (2014).

n/a, not applicable.

was minimal for systolic blood pressure $\left(\mathrm{I}^{2}=8.6, \mathrm{p}=0.341\right)$ but extensive for diastolic blood pressure $\left(\mathrm{I}^{2}=52.6, \mathrm{p}=0.001\right)$, and not explained by any single study. None of the variables in the meta-regressions (table 5) had significant associations with diastolic blood pressure or reduced the heterogeneity appreciably (residual $\mathrm{I}^{2}>50$ ).

Table 4 Average biomarker characteristics prior to intervention in controlled trials of 34 adult sedentary behaviour interventions $\geq 7$ days with biomarker outcomes

\begin{tabular}{|c|c|c|c|c|c|c|}
\hline & k & $\mathbf{n}$ & $\begin{array}{l}\text { Weighted } \\
\text { mean } \pm \text { pooled SD }\end{array}$ & $\begin{array}{l}\text { Study means } \\
\text { (min-max) }\end{array}$ & Study with lowest mean & Study with highest mean \\
\hline Weight, kg & 29 & 2456 & $71.3 \pm 10.6$ & $62.2-99.6$ & Alkhajah et $a^{68}$ & MacEwen et al ${ }^{40}$ \\
\hline Body mass index, $\mathrm{kg} / \mathrm{m}^{2}$ & 34 & 3186 & $25.4 \pm 3.2$ & $22.1-35.9$ & Alkhajah et a ${ }^{68}$ & Schuna et $\left.a\right|^{56}$ \\
\hline Waist circumference, $\mathrm{cm}$ & 21 & 2630 & $83.9 \pm 7.7$ & $74.4-111.4$ & Butler et $a l^{74}$ & MacEwen et a ${ }^{40}$ \\
\hline Body fat, $\%$ & 18 & 2050 & $28.1 \pm 5.4$ & $24.5-45.5$ & Dunning et $a l^{75}$ & Kozey Keadle et $\left.a\right|^{58}$ \\
\hline Fat mass, $\mathrm{kg}$ & 7 & 753 & $25.3 \pm 7.7$ & $18.4-32.3$ & Alkhajah et $a^{68}$ & Kallings et $a l^{70}$ \\
\hline Fat-free mass, kg & 8 & 1252 & $40.0 \pm 6.7$ & $44.1-56.5$ & Alkhajah et $a^{68}$ & Balducci et $a l^{72}$ \\
\hline Systolic BP, mm Hg & 25 & 2461 & $110.0 \pm 10.5$ & $109-142$ & Dunning et $a l^{75}$ & Maxwell-Smith et al \\
\hline Diastolic BP, mm Hg & 25 & 2457 & $68.4 \pm 6.5$ & $69-86$ & Peterman et $\left.a\right|^{83}$ & $\begin{array}{l}\text { MacEwen et al }{ }^{40} \text {; Maxwell-Smith } \\
\text { et al }{ }^{40}\end{array}$ \\
\hline Glucose, mM & 19 & 1975 & $4.7 \pm 1.0$ & $4.1-7.6$ & Peterman et $a l^{83}$ & Balducci et $a l^{72}$ \\
\hline Insulin, pM & 11 & 1495 & $51.5 \pm 44.1$ & $37.1-133.0$ & Dunning et $a l^{75}$ & Kozey Keadle et $a l^{58}$ \\
\hline $\mathrm{HbA1c}, \%$ & 11 & 1308 & $4.4 \pm 0.6$ & $4.9-7.4$ & Kallings et $a l^{70}$ & Balducci et $a l^{72}$ \\
\hline Total cholesterol, mM & 24 & 2292 & $4.3 \pm 0.6$ & $4.0-5.5$ & Peterman et $a l^{83}$ & Kallings et $a l^{70}$ \\
\hline HDL cholesterol, mM & 22 & 2232 & $1.2 \pm 0.4$ & $1.1-1.8$ & Peterman et $a l^{83}$ & Pesola et $a^{38}$ \\
\hline LDL cholesterol, mM & 21 & 2142 & $2.5 \pm 0.8$ & $2.5-3.3$ & Peterman et $a l^{83}$ & Kallings et $a l^{70}$ \\
\hline Triglycerides, mM & 23 & 2202 & $1.1 \pm 0.5$ & $0.9-1.9$ & Alkhajah et $a^{68}$ & Kozey Keadle et $a l^{58}$ \\
\hline
\end{tabular}

BP, blood pressure; HDL, high-density lipoprotein; $k$, number of interventions; LDL, low-density lipoprotein; $n$, number of participants. 
Table 5 Associations of study characteristics with intervention effects on cardiometabolic biomarkers (meta-regression)

\begin{tabular}{|c|c|c|c|c|c|c|c|c|}
\hline & Unadjuste & & & & Age adjus & & & \\
\hline & $k, n$ & b $(95 \% \mathrm{Cl})$ & $P$ value & $\mathrm{I}^{2}$, p value & $k, n$ & b $(95 \% \mathrm{Cl})$ & $P$ value & $\mathrm{I}^{2}, \mathrm{p}$ value \\
\hline Waist circumference, $\mathrm{cm}$ & 19, 2076 & & & $45.8 \%, p=0.016$ & 19, 2076 & & & $45.8 \%, p=0.016$ \\
\hline Mean baseline age, per $10 y$ & 18,2050 & $-0.50(-1.18$ to 0.17$)$ & 0.144 & $51.6 \%, p=0.007$ & & - & - & - \\
\hline Mean baseline $\mathrm{BMI}, \mathrm{kg} / \mathrm{m}^{2}$ & 19,2076 & $-0.04(-0.25$ to 0.16$)$ & 0.672 & $48.6 \%, p=0.011$ & 18,2050 & $-0.01(-0.24$ to 0.22$)$ & 0.910 & $54.5 \%, p=0.005$ \\
\hline Mean baseline level & 19, 2076 & $0.01(-0.08$ to 0.09$)$ & 0.856 & $44.9 \%, p=0.021$ & 18,2050 & $0.07(-0.03$ to 0.18$)$ & 0.182 & $45.9 \%, p=0.023$ \\
\hline Sedentary effectiveness, h/day* & 19,2076 & $-0.62(-1.42$ to 0.18$)$ & 0.127 & $38.7 \%, p=0.048$ & 18,2050 & $-1.05(-1.96$ to -0.14$)$ & 0.023 & $40.3 \%, p=0.049$ \\
\hline$>6$ months & & $-0.36(-2.28$ to 1.57$)$ & 0.717 & & & $-0.25(-2.28$ to 1.78$)$ & 0.809 & \\
\hline Risk of bias (vs high risk) & 19,2076 & & 0.098 & $22.6 \%, p=0.192$ & 18,2050 & & 0.109 & $25.4 \%, p=0.174$ \\
\hline Some concerns & & $-0.70(-2.50$ to 1.09$)$ & 0.441 & & & $-0.52(-2.39$ to 1.34$)$ & 0.582 & \\
\hline Low risk & & $-1.47(-3.10$ to 0.16$)$ & 0.077 & & & $-1.36(-3.03$ to 0.31$)$ & 0.110 & \\
\hline Fat-free mass, kg & 7,1011 & & & $72.7 \%, p=0.001$ & 7,1011 & & & $72.7 \%, p=0.001$ \\
\hline Duration ( $>6$ vs $\leq 3$ months) $\dagger$ & 7,1011 & 0.06 (1.23 to 1.36$)$ & 0.922 & $77.1 \%, p<0.001$ & 7,1011 & $-0.14(-1.86$ to 1.58$)$ & 0.875 & $77.6 \%, p=0.001$ \\
\hline Risk of bias (vs high risk) & 7,1011 & & 0.490 & $69.9 \%, p=0.010$ & 7,1011 & & 0.619 & $74.5 \%, p=0.008$ \\
\hline Some concerns & & $0.72(-0.53$ to 1.98$)$ & 0.258 & & & $1.23(-0.73$ to 3.20$)$ & 0.219 & \\
\hline Low risk & & $0.12(-1.10$ to 1.34$)$ & 0.847 & & & $0.37(-1.07$ to 1.81$)$ & 0.615 & \\
\hline Glucose, mM & 19,1518 & & & $45.5 \%, p=0.017$ & 19,1518 & & & $45.5 \%, p=0.017$ \\
\hline Mean baseline age, per 10 years & 19,1518 & $-0.01(-0.08$ to 0.07$)$ & 0.891 & $47.9 \%, p=0.012$ & & - & - & - \\
\hline Mean baseline BMI, $\mathrm{kg} / \mathrm{m}^{2}$ & 19,1518 & $0.01(-0.01$ to 0.03$)$ & 0.391 & $46.0 \%, p=0.017$ & 19,1518 & $0.01(-0.01$ to 0.04$)$ & 0.330 & $48.8 \%, p=0.012$ \\
\hline Mean baseline level & 18,1497 & $-0.01(-0.23$ to 0.20$)$ & 0.908 & $45.8 \%, p=0.021$ & 18,1497 & $0.03(-0.23$ to 0.29$)$ & 0.819 & $46.0 \%, p=0.023$ \\
\hline Sedentary effectiveness, h/day* & 18,1497 & $-0.02(-0.21$ to 0.16$)$ & 0.804 & $45.6 \%, p=0.021$ & 18,1497 & $-0.05(-0.25$ to 0.15$)$ & 0.632 & $46.0 \%, p=0.023$ \\
\hline Duration (vs $\leq 3$ months) & 19,1518 & & 0.611 & $51.5 \%, p=0.007$ & 19,1518 & & 0.732 & $54.0 \%, p=0.005$ \\
\hline $3-6$ months & & $-0.00(-0.19$ to 0.19$)$ & 0.980 & & & $0.04(-0.24$ to 0.32$)$ & 0.769 & \\
\hline Mean baseline level & 10,1102 & 0.15 (0.03 to 0.27$)$ & 0.018 & $61.1 \%, p=0.008$ & 10,1102 & $0.21(0.12$ to 0.31$)$ & $<0.001$ & $0.0 \%, p=0.641$ \\
\hline Sedentary effectiveness, hour/day* & 10,1102 & $1.65(-6.15$ to 9.45$)$ & 0.678 & $66.5 \%, p=0.002$ & 10,1102 & $3.51(-6.34$ to 13.35$)$ & 0.485 & $45.4 \%, p=0.077$ \\
\hline Duration (vs $\leq 3$ months) & 10,1102 & & 0.014 & $50.8 \%, p=0.047$ & 10,1102 & & 0.268 & $57.8 \%, p=0.027$ \\
\hline $3-6$ months & & $2.14(-7.20$ to 11.48$)$ & 0.654 & & & $1.87(-8.64$ to 12.38$)$ & 0.728 & \\
\hline$>6$ months & & $7.87(-0.21$ to 15.95$)$ & 0.056 & & & $6.84(-2.33$ to 16.01$)$ & 0.144 & \\
\hline Risk of bias (vs high risk) & 10,1102 & & $<0.001$ & $11.9 \%, p=0.338$ & 10,1102 & & 0.211 & $22.8 \%, p=0.255$ \\
\hline Some concerns & & $-0.24(-1.42$ to 0.94$)$ & 0.692 & & & $-3.10(-11.81$ to 5.62$)$ & 0.486 & \\
\hline Low risk & & $-4.64(-6.95$ to -2.32$)$ & $<0.001$ & & & $-5.60(-11.33$ to 0.14$)$ & 0.056 & \\
\hline HbA1c, \% & 9,892 & & & $72.9 \%, p=0.000$ & 9,892 & & & $72.9 \%, p=0.000$ \\
\hline Mean baseline age, per 10 years & 9,892 & $-0.10(-0.18$ to -0.02$)$ & 0.011 & $49.5 \%, p=0.054$ & & - & - & - \\
\hline Mean baseline $\mathrm{BMI}, \mathrm{kg} / \mathrm{m}^{2}$ & 9,892 & $-0.01(-0.05$ to 0.03$)$ & 0.599 & $76.3 \%, p<0.001$ & 9,892 & $-0.03(0.05$ to -0.01$)$ & 0.004 & $0.0 \%, p=0.454$ \\
\hline Mean baseline level & 9,892 & $-0.15(-0.34$ to 0.04$)$ & 0.127 & $76.3 \%, p<0.001$ & 9,892 & $-0.16(-0.32$ to 0.00$)$ & 0.055 & $49.1 \%, p=0.067$ \\
\hline Sedentary effectiveness, hour/day* & 9,892 & $0.08(-0.10$ to 0.26$)$ & 0.379 & $69.5 \%, p=0.002$ & 9,892 & $-0.02(-0.20$ to 0.17$)$ & 0.862 & $56.4 \%, p=0.032$ \\
\hline Duration (vs $\leq 3$ months) & 9, 892 & & 0.994 & $78.0 \%, p<0.001$ & 9,892 & & 0.002 & $24.7 \%, p=0.249$ \\
\hline $3-6$ months & & $-0.02(-0.35$ to 0.32$)$ & 0.919 & & & $0.04(-0.14$ to 0.23$)$ & 0.641 & \\
\hline$>6$ months & & $-0.02(-0.38$ to 0.35$)$ & 0.932 & & & $-0.24(-0.50$ to 0.02$)$ & 0.069 & \\
\hline Risk of bias (vs high risk) & 9,892 & & 0.090 & $75.4 \%, p<0.001$ & 9,892 & & 0.037 & $59.4 \%, p=0.031$ \\
\hline Some concerns & & $0.30(-0.25$ to 0.85$)$ & 0.287 & & & $0.28(-0.23$ to 0.79$)$ & 0.286 & \\
\hline Low risk & & $0.50(-0.02$ to 1.02$)$ & 0.058 & & & $0.40(-0.09$ to 0.89$)$ & 0.113 & \\
\hline $\begin{array}{l}\text { Diastolic blood pressure, } \mathrm{mm} \\
\mathrm{Hg}\end{array}$ & 25,1932 & & & $52.6 \%, p=0.001$ & 25,1932 & & & $52.6 \%, p=0.001$ \\
\hline Mean baseline age, per 10 years & 25,1932 & $-0.38(-1.30$ to 0.54$)$ & 0.421 & $54.4 \%, p<0.001$ & & - & - & - \\
\hline Mean baseline $\mathrm{BMI}, \mathrm{kg} / \mathrm{m}^{2}$ & 24,1903 & $-0.01(-0.32$ to 0.30$)$ & 0.946 & $53.2 \%, p=0.001$ & 24,1903 & $0.03(-0.31$ to 0.36$)$ & 0.885 & $55.2 \%, p=<0.001$ \\
\hline
\end{tabular}


Table 5 Continued

\begin{tabular}{|c|c|c|c|c|c|c|c|c|}
\hline & \multicolumn{4}{|c|}{ Unadjusted } & \multicolumn{4}{|c|}{ Age adjusted } \\
\hline & $k, n$ & b $(95 \% \mathrm{Cl})$ & $P$ value & $\mathrm{I}^{2}, \mathrm{p}$ value & $k, n$ & b $(95 \% \mathrm{Cl})$ & $P$ value & $I^{2}, p$ value \\
\hline Mean baseline level & 24,1911 & $-0.16(-0.44$ to 0.12$)$ & 0.250 & $52.0 \%, p=0.002$ & 24,1911 & $-0.11(-0.42$ to 0.20$)$ & 0.492 & $52.5 \%, p=0.002$ \\
\hline Sedentary effectiveness, hour/day* & 23,1882 & $-1.07(-2.83$ to 0.69$)$ & 0.232 & $52.9 \%, p=0.002$ & 23,1882 & $-1.69(-3.40$ to 0.02$)$ & 0.053 & $43.2 \%, p=0.019$ \\
\hline Duration (vs $\leq 3$ months) & 25,1932 & & 0.655 & $56.2 \%, p<0.001$ & 25,1932 & & 0.712 & $57.9 \%, p=<0.001$ \\
\hline $3-6$ months & & $0.22(-2.50$ to 2.94$)$ & 0.874 & & & $0.40(-2.64$ to 3.43$)$ & 0.798 & \\
\hline$>6$ months & & $-1.20(-3.97$ to 1.57$)$ & 0.397 & & & $-1.14(-4.19$ to 1.92$)$ & 0.465 & \\
\hline Risk of bias (vs high risk) & 25,1932 & & 0.699 & $55.1 \%, p<0.001$ & 25,1932 & & 0.629 & $57.1 \%, p=<0.001$ \\
\hline Some concerns & & $1.20-2.05$ to 4.45$)$ & 0.468 & & & $1.82(1.90$ to 5.53$)$ & 0.338 & \\
\hline Low risk & & $1.03(-1.58$ to 3.64$)$ & 0.439 & & & 1.35 (1.56 to 4.25$)$ & 0.363 & \\
\hline Total cholesterol, mM & 23,1798 & & & $54.1 \%, p=0.001$ & 23,1798 & & & $54.1 \%, p=0.001$ \\
\hline Mean baseline age, per 10 years & 23,1798 & $-0.14(-0.22$ to -0.07$)$ & $<0.001$ & $17.1 \%, p=0.233$ & & - & - & - \\
\hline Mean baseline $\mathrm{BMI}, \mathrm{kg} / \mathrm{m}^{2}$ & 23,1798 & $0.01(-0.02$ to 0.04$)$ & 0.664 & $54.6 \%, p=0.001$ & 23,1798 & $0.01(-0.01$ to 0.03$)$ & 0.398 & $17.4 \%, p=0.233$ \\
\hline Mean baseline level & 23,1798 & $-0.24(-0.50$ to 0.02$)$ & 0.066 & $45.7 \%, p=0.011$ & 23,1798 & $-0.05(-0.30$ to 0.21$)$ & 0.713 & $20.6 \%, p=0.195$ \\
\hline Sedentary effectiveness, hour/day* & 23,1798 & $0.08(-0.04$ to 0.20$)$ & 0.206 & $40.3 \%, p=0.027$ & 23,1798 & $0.01(-0.10$ to 0.12$)$ & 0.812 & $19.5 \%, p=0.208$ \\
\hline Duration (vs $\leq 3$ months) & 23,1798 & & 0.573 & $54.6 \%, p=0.001$ & 23,1798 & & 0.003 & $20.4 \%, p=0.202$ \\
\hline $3-6$ months & & $0.07(-0.17$ to 0.31$)$ & 0.577 & & & $0.06(-0.12$ to 0.24$)$ & 0.493 & \\
\hline$>6$ months & & $0.13(-0.12$ to 0.39$)$ & 0.306 & & & $0.11(-0.08$ to 0.30$)$ & 0.259 & \\
\hline Risk of bias (vs high risk) & 23,1798 & & 0.044 & $47.2 \%, p=0.009$ & 23,1798 & & $<0.001$ & $13.7 \%, p=0.284$ \\
\hline Some concerns & & $-0.34(-0.65$ to -0.04$)$ & 0.028 & & & $-0.21(-0.48$ to 0.06$)$ & 0.134 & \\
\hline Low risk & & $-0.11(-0.39$ to 0.16$)$ & 0.419 & & & $-0.05(-0.29$ to 0.19$)$ & 0.689 & \\
\hline Triglycerides, mM & 23,1742 & & & $49.0 \%, p=0.005$ & 23,1742 & & & $49.0 \%, p=0.005$ \\
\hline Mean baseline age, per $10 y$ & 23,1742 & $-0.05(-0.11$ to 0.02$)$ & 0.149 & $51.3 \%, p=0.003$ & & - & - & - \\
\hline Mean baseline $\mathrm{BMI}, \mathrm{kg} / \mathrm{m}^{2}$ & 23,1742 & $0.00(-0.02$ to 0.02$)$ & 0.962 & $50.3 \%, p=0.004$ & 23,1742 & $0.01(-0.02$ to 0.03$)$ & 0.667 & $52.4 \%, p=0.003$ \\
\hline Mean baseline level & 22,1721 & $-0.20(-0.63$ to 0.22$)$ & 0.350 & $45.1 \%, p=0.014$ & 22,1721 & $-0.13(-0.53$ to 0.26$)$ & 0.508 & $31.7 \%, p=0.087$ \\
\hline Sedentary effectiveness, h/day* & 22,1721 & $-0.06(-0.17$ to 0.05$)$ & 0.279 & $45.9 \%, p=0.012$ & 22,1721 & $-0.13(-0.21$ to -0.05$)$ & 0.001 & $0.0 \%, p=0.507$ \\
\hline Duration (vs $\leq 3$ months) & 23,1742 & & 0.645 & $53.4 \%, p=0.002$ & 23,1742 & & 0.447 & $55.7 \%, p=0.001$ \\
\hline $3-6$ months & & $-0.07(-0.24$ to 0.10$)$ & 0.402 & & & $-0.05(-0.24$ to 0.14$)$ & 0.639 & \\
\hline$>6$ months & & $-0.06(-0.25$ to 0.13$)$ & 0.516 & & & $-0.07(-0.28$ to 0.13$)$ & 0.481 & \\
\hline Risk of bias (vs high risk) & 23,1742 & & 0.396 & $53.6 \%, p=0.002$ & 23,1742 & & 0.485 & $55.7 \%, p=0.001$ \\
\hline Some concerns & & $-0.13(-0.33$ to 0.07$)$ & 0.218 & & & $-0.07(-0.34$ to 0.19$)$ & 0.587 & \\
\hline Low risk & & $-0.10(-0.28$ to 0.07$)$ & 0.245 & & & $-0.06(-0.28$ to 0.16$)$ & 0.573 & \\
\hline
\end{tabular}

Table presents unstandardised regression coefficient (b) and $95 \% \mathrm{Cl}$ and p value from meta-regression of controlled trials of adult sedentary behaviour interventions $\geq 7$ days. Italics indicates overall $p$ value (omnibus test).

$\mathrm{k}=$ total number of interventions included and $\mathrm{n}=$ total number of individuals analysed in the included interventions, in the meta-regressions or main meta-analysis (boldface).

Residual heterogeneity ( $\mathrm{I}^{2}$ and $\mathrm{p}$ from Cochrane's $\mathrm{Q}$ test) with overall heterogeneity in the main meta-analysis shown in boldface.

*Estimated effectiveness of intervention on overall sedentary time (net of control).

tNo studies in the 3-6 months duration category.

$\mathrm{BMI}$, body mass index.

\section{Glucose metabolism}

Prior to intervention, fasting glucose averaged $4.7 \pm 1.0 \mathrm{mM}$, indicating levels consistent with healthy metabolism or prediabetes rather than diabetes. However, the studies covered a diverse spectrum from $4.1 \mathrm{mM}$ in a study of healthy adults ${ }^{83}$ to $7.6 \mathrm{mM}$ in a study of type 2 diabetes patients aged $40-80$ years. ${ }^{72}$ Baseline insulin and HbA1c levels averaged $51.5 \pm 44.1 \mathrm{pM}$ and $4.4 \% \pm 0.6 \%$ were also quite variable across studies (table 3 and online supplementary table S5). Pooled effects pointed to small benefits to glucose metabolism, which were statistically significant only for fasting insulin $(-1.42 \mathrm{pM}, 95 \% \mathrm{CI}-2.82$ to 0.02 ) and small non-significant tendencies towards lower fasting glucose $(-0.03 \mathrm{mM}, 95 \% \mathrm{CI}-0.11$ to 0.05$)$ and $\mathrm{HbA} 1 \mathrm{c}$ $(-0.10 \%, 95 \% \mathrm{CI}-0.22 \%$ to $0.03 \%)$. Forest plots are shown in online supplementary figure 9-11. Small-study effects may have overstated effects on insulin and HbA1c.

Glucose, insulin and HbA1c all showed substantial heterogeneity $\left(\mathrm{I}^{2}=45.5\right.$ for glucose to $\mathrm{I}^{2}=72.9$ for insulin; $\left.\mathrm{p}<0.05\right)$, which remained present in all the leave-one-out sensitivity analyses, except for glucose, where removing a single workplace study $^{49}$ that had failed to elicit changes in sedentary behaviour markedly attenuated the heterogeneity $\left(\mathrm{I}^{2}=28.4, \mathrm{p}=0.126\right)$.
Insulin outcomes were significantly beneficially associated with lower baseline levels, shorter intervention duration and higher RoB, with limited residual heterogeneity after accounting for $\operatorname{RoB}\left(\mathrm{I}^{2}=11.9, \mathrm{p}=0.338\right)$; however, only the association with baseline level remained significant accounting for age (residual $\mathrm{I}^{2}=0.0, \mathrm{p}=0.641$ ). Higher participant age significantly predicted enhanced HbA1c outcomes, and led to lower heterogeneity (residual $\mathrm{I}^{2}=49.5, \mathrm{p}=0.054$ ) while in age-adjusted models, effects were significantly beneficially associated with higher $\mathrm{BMI}$, longer intervention duration and lower RoB, and a borderline association with higher baseline levels. The model with age and BMI had no residual heterogeneity $\left(\mathrm{I}^{2}=0.0, \mathrm{p}=0.454\right)$.

\section{Lipid metabolism}

Prior to intervention, baseline levels averaged $4.3 \pm 0.6 \mathrm{mM}$ total cholesterol, $1.2 \pm 0.4 \mathrm{mM}$ HDL, $2.5 \pm 0.8 \mathrm{mM}$ LDL and $1.1 \pm 0.5 \mathrm{mM}$ triglycerides, with comparatively limited variation across studies relative to other biomarkers (table 4, online supplementary table S5). Small significant improvements in response to sedentary behaviour interventions were seen in HDL cholesterol $(0.04 \mathrm{mM}, 95 \% \mathrm{CI} 0.02$ to 0.07$)$ alongside 
a small, non-significant improvement in total cholesterol $(-0.06 \mathrm{mM}, 95 \% \mathrm{CI}-0.16$ to 0.04$)$ and very small, nonsignificant effects on LDL cholesterol $(-0.02 \mathrm{mM}, 95 \% \mathrm{CI}$ -0.07 to 0.04$)$, and triglycerides $(-0.02 \mathrm{mM}, 95 \% \mathrm{CI}-0.09$ to 0.04$)$. Forest plots for cholesterol and triglycerides are shown in online supplementary figure S12 and online supplementary figure 13-15. Small-study effects if anything limited the effects seen for lipid metabolism, with trimmed-and-filled estimates all either larger or virtually unchanged, and with a significant effect on total cholesterol emerging $(-0.10 \mathrm{mM}$, $95 \%$ CI -0.20 to 0.00$)$.

There was limited heterogeneity in outcomes concerning HDL and LDL cholesterol $\left(\mathrm{I}^{2}<25, \mathrm{p} \geq 0.05\right)$ and more substantial and significant heterogeneity in total cholesterol $\left(\mathrm{I}^{2}=54.1, \mathrm{p}=0.001\right)$ and triglycerides $\left(\mathrm{I}^{2}=49.0, \mathrm{p}=0.005\right)$. Removing one study ${ }^{36}$ markedly lowered the total cholesterol heterogeneity $\left(\mathrm{I}^{2}=21.1, \mathrm{p}=0.183\right)$ while the same was not the case for triglycerides. Meta-regressions (table 5) showed significantly greater reductions in total cholesterol were seen with higher age, and higher RoB, with limited residual heterogeneity left after accounting for age $\left(\mathrm{I}^{2}=17.1, \mathrm{p}=0.233\right)$ while in age-adjusted models, significant predictors of greater reductions were shorter study duration and higher RoB. It appears multiple factors may have contributed to the heterogeneity in triglyceride outcomes. None of the variables significantly predicted effects on triglycerides and residual heterogeneity remained high in all models (residual $\mathrm{I}^{2}=45.1-53.6$ ). In ageadjusted models, less effectiveness in improving sedentary behaviour outcomes significantly predicted greater reductions in triglycerides $(-0.13 \mathrm{mM}, 95 \% \mathrm{CI}-0.21$ to 0.05$)$, with very limited heterogeneity left when considering both these factors simultaneously $\left(\mathrm{I}^{2}=0.0, \mathrm{p}=0.507\right)$, which also involved excluding one study ${ }^{74}$ due to missing data.

\section{DISCUSSION}

Several reviews have reported on sedentary behaviour interventions in relation to sedentary behaviour outcomes 232627 and found them to be effective, to varying degrees. These reviews indicated success seemed to vary depending on factors including the focus on sedentary behaviour (alone vs in combination with other lifestyle behaviours) and the type of intervention (with multicomponent workplace interventions being particularly successful). The current systematic review with meta-analyses considered these interventions in the context of their effect on biomarkers of cardiometabolic health, finding a small body of evidence. In total, 54 studies were identified, with 33 eligible for the meta-analyses, and with 6-25 controlled interventions ultimately included in meta-analyses concerning body anthropometry, blood pressure and haemodynamics, glucose metabolism and lipid metabolism.

Broadly, the meta-analyses provided some support for small improvements in selected indicators of body anthropometry, blood pressure, glucose metabolism and lipid metabolism with intervention, with none of the outcomes tending to worsen with intervention. Specifically, significant improvements were seen in body weight, waist circumference, percentage body fat, systolic blood pressure, insulin and HDL cholesterol. For some outcomes, findings varied widely from study to study, while for others they were quite consistent, with heterogeneity ranging widely $\left(\mathrm{I}^{2}=0.0-72.9\right)$. It may be the case that some types of interventions are effective (and others ineffective), and/or the interventions may be effective in some populations but not others. The sensitivity analyses and meta-regressions provided some insight into potential factors underlying some of the heterogeneous results. Sometimes a single study deviating from the general pattern appeared to be the issue, while other key factors (different for each outcome) tended to be due to participant age and BMI, study duration and RoB. There were very few studies with each characteristic; consequently, the CIs around effects were quite wide, and findings should not be taken to indicate non-significant predictors in the metaregressions were unimportant. The low number of studies was also the reason stratified analyses were not performed to inform the effectiveness of specific types of interventions, for specific populations (eg, men, women, older adults and those with clinical conditions such as type 2 diabetes). Some potential success factors not able to be explored were ethnicity (poorly reported), sex, behaviour settings and dose response. Prior findings have sometimes suggested the biological responses to sedentary time may vary depending on the setting or context in which it occurs, ${ }^{88} 89$ by ethnicity, ${ }^{90-92}$ by sex ${ }^{18} 919394$ and by the activity replacing sedentary time. ${ }^{95-98}$

The systematic review showed some key considerations for interpreting the effectiveness findings. The sedentary behaviour interventions performed were highly varied in terms of their setting, use of behavioural change components, and the degree of emphasis on sedentary behaviour; thus, the heterogeneous outcomes were not highly surprising. Also, some caution should be exerted in extrapolating findings to groups with limited or no representation in the evidence base. Evidence has mostly been collected from studies of Caucasian or 'white' populations (variously defined) of working age, often with overweight/obese BMI or waist circumference, with very limited representation of those with clinical conditions pertinent to cardiovascular health, such as type 2 diabetes. The short duration of most interventions may have influenced the degree of effectiveness observed in the meta-analyses; there was a paucity of studies intervening $\geq 12$ months and including maintenance evaluations from which to consider sustainability or determine what may happen in the longer term. Previously, it has been reported that biomarker results have been more promising at 12 months compared with 3 months, despite sitting reduction being greatest at 3 months. ${ }^{43}$

To overcome the limitations of the current evidence base the next logical step would be individual patient data metaanalysis, with interventions collecting 'dose' data regarding sedentary behaviour and the activities that may replace it in the most harmonisable way possible, even if this is only possible in a subsample of participants. Ideally, the measurement should allow both calculation of some total dose (eg, in MET hours), as well as partial out time spent sedentary and in various alternative behaviours, delineated by intensity, posture and accumulation method (eg, sedentary/sitting, standing, light movement, moderate movement, vigorous movement and bouted vs non-bouted forms of the relevant behaviours). Such an approach may help to determine the populations for which each intervention may be effective, as well as ascertain which specific behaviours (if any) may achieve the greatest biomarker improvements.

Other key features identified within the current evidence base are the type, reporting (or lack thereof) and specificity/sensitivity of biomarker outcomes collected. For example, most of the biomarkers collected (eg, blood glucose, insulin, triglycerides and blood pressure) are subject to homeostatic regulation but were only measured in fasted or resting states. It is important to also evaluate how some sensitive biomarkers (without these limitations) that have fairly consistently responded beneficially 
in acute laboratory interventions lasting $<7$ days $^{911}{ }^{1299}$ respond over longer intervention timeframes. Specifically, postprandial glucose, insulin, triglycerides and ambulatory blood pressure should be measured. Other understudied outcomes that are potentially useful to measure are: detailed markers of vascular haemodynamics and structure (eg, cardiovascular and cerebrovascular blood flow, flow-mediated dilatation and arterial stiffness) ${ }^{99}{ }^{100}$; C-peptide; continuous glucose monitoring; postprandial lipids; lipid subclasses ${ }^{101} 102$; site-specific tissue samples (eg, muscle, adipose tissue) and additional intermediate biomarkers (such as those related to systemic metabolic/ oxidative stress and inflammation). ${ }^{9100}$ These outcomes could be collected in all participants or in subsamples, as they represent opportunities to detect changes that might otherwise be missed, and improve our understanding of shared risk factors and potential mechanistic pathways.

There were some caveats regarding the overall quality of the evidence. Trimmed-and-filled results mostly suggested publication bias did not affect findings, but the insulin finding may be overstated and some of the lipid findings understated. Inferences were sometimes made from a very small number of studies (especially regarding biomarkers of glucose and lipid metabolism), which is especially concerning with the findings varying so much between studies. The paucity of 'low' RoB studies is a limitation, though importantly most studies had an 'unclear' rather than a 'high' RoB and the meta-regressions did not usually show high RoB equated to the most promising results (if anything, findings showed the opposite).

\section{What is already known}

- Recent reviews have demonstrated sedentary-reduction interventions are effective at modifying behaviour (reducing sitting).

- Observational and experimental research (mostly acute laboratory-based work) links both high volumes and prolonged periods of sedentary behaviour (sitting) with adverse health outcomes.

- However, less is known about the nature and extent of health effects with sedentary behaviour interventions over longer periods and under free-living conditions.

\section{What are the new findings}

- This review evaluated the evidence regarding the impact that interventions to reduce sedentary behaviour, alone or in combination with physical activity increases, may have on important indicators of cardiometabolic risk, when intervening for $\geq 7$ days under free-living conditions.

- Available evidence for different outcomes ranged from 6 to 25 controlled trials. On average, these interventions led to modest improvements in selected indicators of body anthropometry, glucose and lipid metabolism, and blood pressure regulation, with no adverse effects observed.

- Potential improvements for future research were noted: more high-quality studies and interventions > 12 months; more population diversity (based on ethnicity, age, and clinical factors); more sensitive biological indicators; and, more studies evaluating vascular function and inflammation.

\section{CONCLUSIONS}

This systematic review with meta-analyses synthesised the body of work concerning the effectiveness of sedentary behaviour interventions on biomarkers of cardiometabolic risk, specifically: body anthropometry; blood pressure and related haemodynamics; glucose metabolism; lipid metabolism and inflammation. Consistent with evidence from prior observational research and acute laboratory-based experiments $(<7$ days) linking sedentary behaviour with cardiometabolic health, ${ }^{811} 12$ the evidence from $\geq 7$ days interventions in free-living conditions showed small improvements in some cardiometabolic biomarkers. These biomarker improvements definitively occurred in response to interventions targeting sedentary behaviour (alone or alongside physical activity), but how they occurred in response to sedentary reductions and increases in various forms of physical activity remains unclear. Our review indicated that studies in clinical populations, ethnicities other than Caucasian or 'white' in predominantly Western countries, and evaluation of biomarkers of inflammation and postprandial metabolism are key areas for future research.

\section{Author affiliations}

${ }^{1}$ Centre for Urban Transitions, Swinburne University of Technology, Melbourne, VIC, Australia

${ }^{2}$ Baker Heart and Diabetes Institute, Melbourne, VIC, Australia

${ }^{3}$ School of Public Health, The University of Queensland, Brisbane, QLD, Australia

${ }^{4}$ The Alfred Hospital, Melbourne, VIC, Australia

${ }^{5}$ Central Clinical School/Department of Epidemiology and Preventive Medicine,

Faculty of Medicine, Nursing and Health Sciences, Monash University, Melbourne, VIC, Australia

${ }^{6}$ Institute of Physical Activity and Nutrition Research, School of Exercise and Nutrition Sciences, Deakin University, Melbourne, VIC, Australia

${ }^{7}$ Mary MacKillop Institute of Health Research, Australian Catholic University,

Melbourne, VIC, Australia

${ }^{8}$ School of Sport Science, Exercise and Health, The University of Western Australia, Perth, WA, Australia

${ }^{9}$ School of Physiotherapy and Exercise Science, Curtin University, Perth, WA, Australia

${ }^{10}$ MRC Epidemiology Unit, Institute of Metabolic Science, University of Cambridge,

Cambridge Biomedical Campus, Cambridge, UK

Correction notice This article has been corrected since it published Online First. The data and formatting in the tables have been updated.

Twitter Paddy C Dempsey @PC_Dempsey

Contributors All authors reviewed the systematic review strategy. LR executed the searches. PCD, NTH, REC, MSG and EW conducted the review and screened the initial results using standardised rules created a priori. PCD, NTH, REC and EW appraised the studies and extracted data from the primary studies and EW analysed the penultimate results. PCD, NTH and EW drafted the manuscript and all authors contributed to the critical revision of the manuscript and approved the final revised version. PCD is the guarantor.

Funding PCD is supported by a National Health and Medical Research Council (NHMRC) of Australia Fellowship (\#1142685) and the UK Medical Research Council [MC_UU_12015/3]. NO, DD and GH are supported by NHMRC of Australia Fellowships (\#1003960, \#1078360 \& \#1086029).

Competing interests None declared.

Patient consent for publication Not required.

Provenance and peer review Not commissioned; externally peer reviewed.

Open access This is an open access article distributed in accordance with the Creative Commons Attribution 4.0 Unported (CC BY 4.0) license, which permits others to copy, redistribute, remix, transform and build upon this work for any purpose, provided the original work is properly cited, a link to the licence is given, and indication of whether changes were made. See: https://creativecommons.org/ licenses/by/4.0\%.

\section{ORCID iD}

Paddy C Dempsey http://orcid.org/0000-0002-1714-6087 


\section{REFERENCES}

1 Roth GA, Johnson C, Abajobir A, et al. Global, regional, and national burden of cardiovascular diseases for 10 causes, 1990 to 2015. J Am Coll Cardiol 2017;70:1-25.

2 GBD 2017 Disease and Injury Incidence and Prevalence Collaborators. Global, regional, and national incidence, prevalence, and years lived with disability for 354 diseases and injuries for 195 countries and territories, 1990-2017: a systematic analysis for the global burden of disease study 2017. Lancet 2018;392:1789-858.

3 Cho NH, Shaw JE, Karuranga S, et al. IDF diabetes atlas: global estimates of diabetes prevalence for 2017 and projections for 2045. Diabetes Res Clin Pract 2018;138:271-81.

4 Tremblay MS, Aubert S, Barnes JD, et al. Sedentary behavior research network (SBRN) - terminology consensus project process and outcome. Int J Behav Nutr Phys Act 2017;14:75.

5 Lynch BM, Mahmood S, Boyle T. Sedentary Behaviour and Cancer. In: Leitzmann MF, Jochem C, Schmid D, eds. Sedentary behaviour epidemiology. Springer series on epidemiology and public health. Cham: Springer International Publishing, 2018: 245-98.

6 Rezende LFMde, Rodrigues Lopes M, Rey-López JP, et al. Sedentary behavior and health outcomes: an overview of systematic reviews. PLoS One 2014;9:e105620.

7 Brocklebank LA, Falconer CL, Page AS, et al. Accelerometer-measured sedentary time and cardiometabolic biomarkers: a systematic review. Prev Med 2015;76:92-102.

8 Chastin SFM, Egerton T, Leask C, et al. Meta-Analysis of the relationship between breaks in sedentary behavior and cardiometabolic health. Obesity 2015;23:1800-10.

9 Dempsey PC, Owen N, Yates TE, et al. Sitting less and moving more: improved glycaemic control for type 2 diabetes prevention and management. Curr Diab Rep 2016;16:114.

10 Benatti FB, Ried-Larsen M. The effects of breaking up prolonged sitting time: a review of experimental studies. Med Sci Sports Exerc 2015;47:2053-61.

11 Saunders TJ, Atkinson HF, Burr J, et al. The acute metabolic and vascular impact of interrupting prolonged sitting: a systematic review and meta-analysis. Sports Med 2018;48:2347-66.

12 Loh R, Stamatakis E, Folkerts D, et al. Effects of interrupting prolonged sitting with physical activity breaks on blood glucose, insulin and triacylglycerol measures: a systematic review and meta-analysis. Sports Med 2020;50:295-330.

13 Larsen RN, Kingwell BA, Sethi P, et al. Breaking up prolonged sitting reduces resting blood pressure in overweight/obese adults. Nutr Metab Cardiovasc Dis 2014;24:976-82.

14 Dempsey PC, Sacre JW, Larsen RN, et al. Interrupting prolonged sitting with brief bouts of light walking or simple resistance activities reduces resting blood pressure and plasma noradrenaline in type 2 diabetes. J Hypertens 2016;34:2376-82.

15 Dunstan DW, Kingwell BA, Larsen $\mathrm{R}$, et al. Breaking up prolonged sitting reduces postprandial glucose and insulin responses. Diabetes Care 2012;35:976-83.

16 Dempsey PC, Blankenship JM, Larsen RN, et al. Interrupting prolonged sitting in type 2 diabetes: nocturnal persistence of improved glycaemic control. Diabetologia 2017;60:499-507.

17 Henson J, Davies MJ, Bodicoat DH, et al. Breaking up prolonged sitting with standing or walking attenuates the postprandial metabolic response in postmenopausal women: a randomized acute study. Diabetes Care 2016:39:130-8.

18 Dempsey PC, Larsen RN, Sethi P, et al. Benefits for type 2 diabetes of interrupting prolonged sitting with brief bouts of light walking or simple resistance activities. Diabetes Care 2016;39:964-72.

19 Duvivier BMFM, Bolijn JE, Koster A, et al. Reducing sitting time versus adding exercise: differential effects on biomarkers of endothelial dysfunction and metabolic risk. Sci Rep 2018;8:8657

20 Piercy KL, Troiano RP, Ballard RM, et al. The physical activity guidelines for Americans. JAMA 2018;320:2020-8.

21 Brown WJ, Bauman AE, Bull FC, et al. Development of evidence-based physical activity recommendations for adults (18-64 years). Report prepared for the Australian government department of health 2012.

22 Department of Health and Social Care, Llwodraeth Cymru Welsh Government, Department of Health Northern Ireland and the Scottish Government. Uk chief medical officers' physical activity guidelines, 2019. Available: https://www.gov. uk/government/publications/physical-activity-guidelines-uk-chief-medical-officersreport;

23 Martin A, Fitzsimons C, Jepson R, et al. Interventions with potential to reduce sedentary time in adults: systematic review and meta-analysis. Br J Sports Med 2015;49:1056-63.

24 Shrestha N, Kukkonen-Harjula KT, Verbeek JH, et al. Workplace interventions for reducing sitting at work. Cochrane Database Syst Rev 2018;6:CD010912.

25 Chu AHY, Ng SHX, Tan CS, et al. A systematic review and meta-analysis of workplace intervention strategies to reduce sedentary time in white-collar workers. Obes Rev 2016;17:467-81

26 Peachey MM, Richardson J, V Tang A, et al. Environmental, behavioural and multicomponent interventions to reduce adults' sitting time: a systematic review and meta-analysis. Br J Sports Med 2020;54:bjsports-2017-098968.
27 Prince SA, Saunders TJ, Gresty K, et al. A comparison of the effectiveness of physical activity and sedentary behaviour interventions in reducing sedentary time in adults: a systematic review and meta-analysis of controlled trials. Obes Rev 2014;15:905-19.

28 Neuhaus M, Eakin EG, Straker L, et al. Reducing occupational sedentary time: a systematic review and meta-analysis of evidence on activity-permissive workstations. Obes Rev 2014;15:822-38.

29 Liberati A, Altman DG, Tetzlaff J, et al. The PRISMA statement for reporting systematic reviews and meta-analyses of studies that evaluate healthcare interventions: explanation and elaboration. BMJ 2009;339:b2700.

30 Stroup DF, Berlin JA, Morton SC, et al. Meta-Analysis of observational studies in epidemiology: a proposal for reporting. meta-analysis of observational studies in epidemiology (moose) group. Jama 2000;283:2008-12.

31 Higgins J, Sterne J, Savović J, et al. A revised tool for assessing risk of bias in randomized trials. Cochrane Methods. In: Cochrane database of systematic reviews, 2016.

32 Cates C. Multiple-arm trial data: using a corrected standard error for GIV analyses. Cochrane Colloquium2015:1-327.

33 van der Pligt $P$, Ball K, Hesketh $K D$, et al. A pilot intervention to reduce postpartum weight retention and central adiposity in first-time mothers: results from the mums OnLiNE (Online, Lifestyle, Nutrition \& Exercise) study. J Hum Nutr Diet 2018;31:314-28

34 Overgaard K, Nannerup K, Lunen MKB, et al. Exercise more or sit less? A randomized trial assessing the feasibility of two advice-based interventions in obese inactive adults. J Sci Med Sport 2018;21:708-13.

35 Yang Y-P, Wang C-J, Wang J-J, et al. The effects of an activity promotion system on active living in overweight subjects with metabolic abnormalities. Obes Res Clin Pract 2017;11:718-27

36 Thomsen T, Aadahl M, Beyer $\mathrm{N}$, et al. The efficacy of motivational counselling and SMS reminders on daily sitting time in patients with rheumatoid arthritis: a randomised controlled trial. Ann Rheum Dis 2017:76:1603-6.

37 Reeves M, Winkler E, Mccarthy N, et al. The living well after breast Cancer ${ }^{\text {TM }}$ pilot trial: a weight loss intervention for women following treatment for breast cancer. Asia Pac J Clin Oncol 2017;13:125-36.

38 Pesola AJ, Laukkanen A, Heikkinen R, et al. Accelerometer-assessed sedentary work, leisure time and cardio-metabolic biomarkers during one year: effectiveness of a cluster randomized controlled trial in parents with a sedentary occupation and young children. PLoS One 2017;12:e0183299.

39 Miyamoto T, Fukuda K, Oshima Y, et al. Non-locomotive physical activity intervention using a tri-axial accelerometer reduces sedentary time in type 2 diabetes. Phys Sportsmed 2017:45:245-51.

40 MacEwen BT, Saunders TJ, MacDonald DJ, et al. Sit-Stand Desks to reduce workplace sitting time in office workers with abdominal obesity: a randomized controlled trial. $J$ Phys Act Health 2017;14:710-5

41 Lyons EJ, Swartz MC, Lewis ZH, et al. Feasibility and acceptability of a wearable technology physical activity intervention with telephone counseling for mid-aged and older adults: a randomized controlled pilot trial. JMIR Mhealth Uhealth 2017; 5:e28.

42 Lin Y-P, Lin C-C, Chen M-M, et al. Short-Term Efficacy of a "Sit Less, Walk More" Workplace Intervention on Improving Cardiometabolic Health and Work Productivity in Office Workers. J Occup Environ Med 2017;59:327-34.

43 Healy GN, Winkler EAH, Eakin EG, et al. A cluster RCT to reduce workers' sitting time: impact on cardiometabolic biomarkers. Med Sci Sports Exerc 2017;49:2032-9.

44 Harris L, Hankey C, Jones $\mathrm{N}$, et al. A cluster randomised control trial of a multicomponent weight management programme for adults with intellectual disabilities and obesity. Br J Nutr 2017;118:229-40.

45 Danquah IH, Kloster S, Holtermann A, et al. Take a Stand!-a multi-component intervention aimed at reducing sitting time among office workers-a cluster randomized trial. Int J Epidemiol 2017;46:128-40.

46 Ball K, Hunter RF, Maple J-L, et al. Can an incentive-based intervention increase physical activity and reduce sitting among adults? the achieve (active choices incentive) feasibility study. Int J Behav Nutr Phys Act 2017:14:35.

47 Balducci S, D'Errico V, Haxhi J, et al. Effect of a behavioral intervention strategy for adoption and maintenance of a physically active lifestyle: the Italian diabetes and exercise study 2 (IDES_2). Diabetes Care 2017;40:1444-52.

48 Thomsen T, Aadahl M, Beyer N, et al. Motivational counselling and SMS-reminders for reduction of daily sitting time in patients with rheumatoid arthritis: a descriptive randomised controlled feasibility study. BMC Musculoskelet Disord 2016;17:434.

49 Taylor WC, Paxton RJ, Shegog R, et al. Impact of booster breaks and computer prompts on physical activity and sedentary behavior among Desk-Based workers: a cluster-randomized controlled trial. Prev Chronic Dis 2016;13:E155.

50 Mailey EL, Rosenkranz SK, Casey K, et al. Comparing the effects of two different break strategies on occupational sedentary behavior in a real world setting: a randomized trial. Prev Med Rep 2016;4:423-8.

51 Rosenberg DE, Gell NM, Jones SMW, et al. The feasibility of reducing sitting time in overweight and obese older adults. Health Educ Behav 2015;42:669-76.

52 Puig-Ribera A, Bort-Roig J, González-Suárez AM, et al. Patterns of Impact Resulting from a 'Sit Less, Move More' Web-Based Program in Sedentary Office Employees. PLoS One 2015;10:e0122474 
53 EFG L, CM R, Shepherd SO, et al. Evaluation of sit-stand workstations in an office setting: a randomised controlled trial. BMC Public Health 2015;15:1145.

54 Biddle SJH, Edwardson CL, Wilmot EG, et al. A randomised controlled trial to reduce sedentary time in young adults at risk of type 2 diabetes mellitus: project stand (sedentary time and diabetes). PLoS One 2015;10:e0143398.

55 Ashe MC, Winters M, Hoppmann CA, et al. "Not just another walking program": Everyday Activity Supports You (EASY) model—a randomized pilot study for a parallel randomized controlled trial. Pilot Feasibility Stud 2015;1:4.

56 Schuna JM, Swift DL, Hendrick CA, et al. Evaluation of a workplace treadmill desk intervention: a randomized controlled trial. J Occup Environ Med 2014;56:1266-76.

57 Mainsbridge CP, Cooley PD, Fraser SP, et al. The effect of an e-health intervention designed to reduce prolonged occupational sitting on mean arterial pressure. J Occup Environ Med 2014;56:1189-94.

58 Kozey Keadle S, Lyden K, Staudenmayer J, et al. The independent and combined effects of exercise training and reducing sedentary behavior on cardiometabolic risk factors. Appl Physiol Nutr Metab 2014;39:770-80.

59 Igelstrom H, Emtner M, Lindberg E, et al. Tailored behavioral medicine intervention for enhanced physical activity and healthy eating in patients with obstructive sleep apnea syndrome and overweight. Sleep Breath 2014;18:655-68.

60 Eakin EG, Winkler EA, Dunstan DW, et al. Living well with diabetes: 24-month outcomes from a randomized trial of telephone-delivered weight loss and physical activity intervention to improve glycemic control. Diabetes Care 2014;37:2177-85.

61 Aadahl M, Linneberg A, Moller TC, et al. Motivational counseling to reduce sitting time: a community-based randomized controlled trial in adults. Am J Prev Med 2014;47:576-86.

62 Morgan PJ, Callister R, Collins CE, et al. The SHED-IT community trial: a randomized controlled trial of internet- and paper-based weight loss programs tailored for overweight and obese men. Ann Behav Med 2013;45:139-52.

63 Koepp GA, Manohar CU, McCrady-Spitzer SK, et al. Treadmill desks: a 1-year prospective trial. Obesity 2013;21:705-11.

64 Healy GN, Eakin EG, Lamontagne AD, et al. Reducing sitting time in office workers: short-term efficacy of a multicomponent intervention. Prev Med 2013;57:43-8.

65 Carr LJ, Karvinen K, Peavler M, et al. Multicomponent intervention to reduce daily sedentary time: a randomised controlled trial. BMJ Open 2013:3:e003261.

66 Verweij LM, Proper KI, Weel ANH, et al. The application of an occupational health guideline reduces sedentary behaviour and increases fruit intake at work: results from an RCT. Occup Environ Med 2012;69:500-7.

67 Steeves JA, Bassett DR, Fitzhugh EC, et al. Can sedentary behavior be made more active? A randomized pilot study of TV commercial stepping versus walking. Int J Behav Nutr Phys Act 2012;9:95.

68 Alkhajah TA, Reeves MM, Eakin EG, et al. Sit-stand workstations: a pilot intervention to reduce office sitting time. Am J Prev Med 2012;43:298-303.

69 John D, Thompson DL, Raynor H, et al. Treadmill workstations: a worksite physical activity intervention in overweight and obese office workers. J Phys Act Health 2011;8:1034-43.

70 Kallings LV, Sierra Johnson J, Fisher RM, et al. Beneficial effects of individualized physical activity on prescription on body composition and cardiometabolic risk factors: results from a randomized controlled trial. Eur I Cardiovasc Prev Rehabil 2009:16:80-4

71 Alonso-Domínguez R, Patino-Alonso MC, Sánchez-Aguadero N, et al. Effect of a multifactorial intervention on the increase in physical activity in subjects with type 2 diabetes mellitus: a randomized clinical trial (EMID study). Eur J Cardiovasc Nurs 2019;18:399-409.

72 Balducci S, D'Errico V, Haxhi J, et al. Effect of a behavioral intervention strategy on sustained change in physical activity and sedentary behavior in patients with type 2 diabetes. JAMA 2019:321:880-90.

73 Bergman F, Wahlstrom V, Stomby A, et al. Treadmill workstations in office workers who are overweight or obese: a randomised controlled trial. Lancet Public Health 2018;3:e523-35.

74 Butler KM, Ramos JS, Buchanan CA, et al. Can reducing sitting time in the University setting improve the cardiometabolic health of college students? Diabetes Metab Syndr Obes 2018:11:603-10.

75 Dunning JR, McVeigh JA, Goble D, et al. The effect of interrupting sedentary behavior on the cardiometabolic health of adults with sedentary occupations: a pilot study. $J$ Occup Environ Med 2018:60:760-7.

76 Garland E, Watts A, Doucette J, et al. Stand up to work: assessing the health impact of adjustable workstations. Intl I of Workplace Health Mgt 2018:11:85-95.

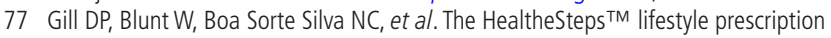
program to improve physical activity and modifiable risk factors for chronic disease: a pragmatic randomized controlled trial. BMC Public Health 2019;19:841.
78 Lai A, Stewart S, Wan A, et al. Development and feasibility of a brief Zero-time exercise intervention to reduce sedentary behaviour and enhance physical activity: a pilot trial. Health Soc Care Community 2019;27:e233-45.

79 Malaeb S, Perez-Leighton CE, Noble EE, et al. A "NEAT" Approach to obesity prevention in the modern work environment. Workplace Health Saf 2019:67:102-10.

80 Mantzari E, Galloway C, Wijndaele K, et al. Impact of sit-stand desks at work on energy expenditure, sitting time and cardio-metabolic risk factors: multiphase feasibility study with randomised controlled component. Prev Med Rep 2019:13:64-72.

81 Maxwell-Smith C, Hince D, Cohen PA, et al. A randomized controlled trial of WATAAP to promote physical activity in colorectal and endometrial cancer survivors. Psychooncology 2019;28:1420-9.

82 Maylor BD, Edwardson CL, Zakrzewski-Fruer JK, et al. Efficacy of a multicomponent intervention to reduce workplace sitting time in office workers: a cluster randomized controlled trial. J Occup Environ Med 2018;60:787-95.

83 Peterman JE, Morris KL, Kram R, et al. Cardiometabolic effects of a workplace cycling intervention. J Phys Act Health 2019;16:547-55.

84 Prince SA, Reed JL, Cotie LM, et al. Results of the sedentary intervention trial in cardiac rehabilitation (SIT-CR study): a pilot randomized controlled trial. Int J Cardiol 2018;269:317-24

85 Resendiz M, Lustik MB, Conkright WR, et al. Standing desks for sedentary occupations: assessing changes in satisfaction and health outcomes after six months of use. Work 2019:63:347-53.

86 Wyke S, Bunn C, Andersen E, et al. The effect of a programme to improve men's sedentary time and physical activity: The European Fans in Training (EuroFIT) randomised controlled trial. PLoS Med 2019;16:e1002736.

87 Zhu W, Gutierrez M, Toledo MJ, et al. Long-Term effects of sit-stand workstations on workplace sitting: a natural experiment. J Sci Med Sport 2018;21:811-6.

88 Dempsey PC, Hadgraft NT, Winkler EAH, et al. Associations of context-specific sitting time with markers of cardiometabolic risk in Australian adults. Int I Behav Nutr Phys Act 2018;15:114

89 Ullrich A, Voigt L, Baumann S, et al. A cross-sectional analysis of the associations between leisure-time sedentary behaviors and clustered cardiometabolic risk. BMC Public Health 2018:18:327.

90 Barone Gibbs B, Pettee Gabriel K, Carnethon MR, et al. Sedentary time, physical activity, and adiposity: cross-sectional and longitudinal associations in cardia. Am J Prev Med 2017;53:764-71.

91 Healy GN, Matthews CE, Dunstan DW, et al. Sedentary time and cardio-metabolic biomarkers in US adults: NHANES 2003-06. Eur Heart J 2011;32:590-7.

92 Yates T, Edwardson CL, Celis-Morales C, et al. Metabolic effects of breaking prolonged sitting with standing or light walking in older South Asians and white Europeans: a randomized acute study. I Gerontol A Biol Sci Med Sci 2020;75:139-46

93 Thorp AA, Healy GN, Owen N, et al. Deleterious associations of sitting time and television viewing time with cardiometabolic risk biomarkers: Australian diabetes, obesity and lifestyle (AusDiab) study 2004-2005. Diabetes Care 2010;33:327-34.

94 Wheeler MJ, Dunstan DW, Ellis KA, et al. Effect of morning exercise with or without breaks in prolonged sitting on blood pressure in older overweight/obese adults. Hypertension 2019;73:859-67.

95 Debache I, Bergouignan A, Chaix B, et al. Associations of Sensor-Derived physical behavior with metabolic health: a compositional analysis in the record Multisensor study. Int J Environ Res Public Health 2019;16:741.

96 Healy GN, Winkler EAH, Owen N, et al. Replacing sitting time with standing or stepping: associations with cardio-metabolic risk biomarkers. Eur Heart J 2015;36:2643-9

97 Chastin SFM, Palarea-Albaladejo J, Dontje ML, et al. Combined effects of time spent in physical activity, sedentary behaviors and sleep on obesity and CardioMetabolic health markers: a novel compositional data analysis approach. PLoS One 2015; 10:e0139984.

98 Winkler EAH, Chastin S, Eakin EG, et al. Cardiometabolic impact of changing sitting, standing, and stepping in the workplace. Med Sci Sports Exerc 2018;50:516-24

99 Dempsey PC, Larsen RN, Dunstan DW, et al. Sitting less and moving more: implications for hypertension. Hypertension 2018;72:1037-46.

100 Dempsey PC, Matthews CE, Dashti SG, et al. Sedentary behavior and chronic disease: mechanisms and future directions.J Phys Act Health 2020:17:52-61.

101 Grace MS, Dempsey PC, Sethi P, et al. Breaking up prolonged sitting alters the postprandial plasma lipidomic profile of adults with type 2 diabetes. J Clin Endocrinol Metab 2017;102:1991-9.

102 O'Keefe JH, Bell DSH. Postprandial Hyperglycemia/Hyperlipidemia (postprandial dysmetabolism) is a cardiovascular risk factor. Am J Cardiol 2007;100:899-904. 